\title{
La consulta previa petrolera en los bloques 20 y 29 de la Amazonia ecuatoriana: entre el desafío y la nostalgia
}

Xavier Izko*

\section{Introducción}

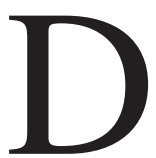

urante los meses de septiembre a diciembre del 2003, se llevó a cabo la primera Consulta Previa Petrolera a los Pueblos Indígenas de la Amazonia Ecuatoriana (Bloques 20 y 29, provincias de Napo, Orellana y Pastaza). La consulta fue coordinada por la Universidad Politécnica Salesiana - UPS, por encargo del Estado (PETROECUADOR) y con el aval de las Federaciones, Juntas Parroquiales y comunidades indígenas de la región.

Con anterioridad a la consulta, y como instancia de preparación de la misma, se había realizado el "Diagnóstico Socio-económico de los bloques 20 y 29" (agosto - noviembre del 2002), que incluía una metodología para la valoración económica de los bienes y servicios ambientales que podrían verse afectados potencialmente por un eventual proceso petrolero; paralelamente, se definió una "Metodología de consulta previa para la negociación de conflictos socio-ambientales". En el marco del diagnóstico fueron elaboradas también bases de datos socio-organizativas de todas las comunidades del área (que fueron luego reajustadas en el marco de la consulta), y propuestas relacionadas con la identificación de compensaciones socioambientales y con el diseño de un Fondo para el Desarrollo Regional. Adicionalmente, se llevaron a cabo 5 talleres sub-regionales para sistematizar las percepciones y experiencias de las comunidades con relación al petróleo. Los resultados de los diagnósticos y la propuesta metodológica fueron socializados con las organizaciones indígenas (febrero del 2003), y avalados por el Estado y por los actores locales 1 .

"Antropólogo, Consultor Internacional y de la Universidad Politécnica Salesiana.

1 Ver UPS 2002 para los resultados del Diagnóstico. El equipo que realizó el diagnóstico estuvo integrado por Xavier Izko (coordinación) y los consultores Diego Burneo, Luis Mejía, Marcelo Mejía, Pablo Ortiz, Severo Rivadeneira, Rocío Vaca y asistentes. 
Posteriormente, a solicitud de las organizaciones indígenas del área y sobre la base de las propuestas realizadas, la Universidad Politécnica Salesiana decidió encargarse de la aplicación de la consulta previa, considerando los lineamientos establecidos en el Reglamento oficial de consulta (diciembre 2002), a fin de que las comunidades pudieran ejercer con plena conciencia sus derechos ciudadanos ${ }^{2}$. Como paso previo a la consulta, se definió una propuesta metodológica que permitiera abarcar los distintos niveles organizativos de las comunidades y alcanzar a la mayoría de la población indígena del área (ver más adelante).

Abordaremos primero, en forma resumida, los principales componentes de la Consulta (metodología, proceso, resultados), para analizar a continuación sus principales proyecciones. Cabe señalar que los contenidos del presente artículo reflejan los consensos alcanzados con los indígenas del área y sus instituciones representativas.

\section{El área de los bloques 20 y 28}

El área total ocupada por ambos bloques es de 448276 ha, que representa el $21.4 \%$ del área total correspondiente a las jurisdicciones de los 8 cantones y 17 parroquias de las tres provincias (Napo, Pastaza y Orellana - 2094171 ha). Algunas parroquias, como Puerto Napo, tienen la totalidad de su territorio dentro de los bloques, mientras que otras, como Chontapunta, apenas el 1.6\%; lo mismo sucede con las 9 Federaciones Indígenas, que están presentes en el territorio de una o varias provincias y atraviesan ambos bloques. En términos jurídico-administrati-

\footnotetext{
2 El pedido de las organizaciones indígenas fue formulado a raíz del Taller de devolución de los resultados del diagnóstico participativo en febrero del 2002, organizado conjuntamente con la FONAKIN (Napo), ANKISH y ACIA (Pastaza). La Universidad ha aceptado el reto de coordinar la Consulta Previa, consciente de que su participación se inscribe en el marco de su mandato institucional, relacionado con sus funciones académicas y con su compromiso en favor de los actores menos favorecidos; por otra parte, con el antecedente del trabajo ya realizado previamente (Diagnóstico participativo del área en el 2002), era necesario crear las condiciones para que las organizaciones locales emitieran un voto responsable frente a la Consulta, proporcionando al mismo tiempo instrumentos de negociación con el Estado y las empresas, y explorando nuevas oportunidades de participación y control social.
} 
vos y políticos, han sido involucradas todas las federaciones y parroquias, aunque su sede estuviera fuera de los bloques.

En términos generales, la confluencia de distintas zonas de vida, microclimas, relieves y paisajes (de montaña, fluviales, selváticos, lacustres), y especies de fauna y flora, confieren a la región un perfil singular en cuanto a existencia de recursos naturales estratégicos, cuya orientación predominante parece ser la conservación de carácter protectivo $(55.5 \%$ de los recursos tienen una vocación relacionada con la protección total y usos muy restringidos); con todo, existen zonas susceptibles de manejo sostenible (sobre todo forestal, no maderable y servicios ambientales) y otras cuya acelerada deforestación debe comenzar a ser equilibrada con prácticas de revegetación parcial e incluso (en las laderas) de conservación de suelos.

Se debe considerar, además, la presencia de prácticas culturales ancestrales, diversamente interpoladas con la cultura occidental, corredores shamánicos, y más de 215 petroglifos y vestigios arqueológicos, que certifican la existencia de una gran riqueza arqueológica, cultural y étnica.

A ello se añade el hecho de que, en términos comparativos, algunos de los cantones de los bloques (Archidona y Tena) constituyen las zonas más densamente pobladas de toda la Amazonia.

En otras palabras, naturaleza y cultura parecen darse la mano para recomendar acciones focalizadas de explotación de recursos no renovables, incluyendo una zonificación final priorizada de los 'lugares sensibles' de la región, a ser respetados por los futuros procesos de exploración y explotación petrolera ${ }^{3}$.

\section{La consulta previa y el reglamento de consulta}

El derecho a la Consulta Previa está amparado por el Convenio 169 de la Organización Internacional del Trabajo-OIT sobre Pueblos Indígenas y Tribales en Países Independientes (1989) y constituye uno de los instrumentos internacionales más avanzados en cuanto al reconocimiento

3 Ver UPS 2002 (Resumen Ejecutivo - conclusiones). 
de los derechos de los pueblos indígenas. Este derecho ha sido recogido por la Constitución de la Repúblicas, la Ley de Gestión Ambiental y el Reglamento Ambiental para operaciones hidrocarburíferas, pasando a ocupar un lugar privilegiado en la pirámide jurídica, conforme al Art. 163 de la Constitución: "Las normas contenidas en los tratados y convenios internacionales, una vez promulgados en el Registro Oficial, formarán parte del ordenamiento jurídico de la República y prevalecerán sobre leyes y otras normas de menor jerarquía".

En términos generales, la ratificación del Convenio 169 de la OIT, el Estado ecuatoriano reconoce el derecho de los pueblos indígenas a participar activamente en el manejo, administración y uso de los recursos ubicados en sus tierras, y el de ser consultados ante actividades de exploración y/o explotación de los mismos, cuando pertenezca al Estado la propiedad de los recursos del subsuelo, lo que constituye un avance significativo respecto a las Constituciones de 1945 y 1978. Como dice el Convenio (Art. 7), a los pueblos afectados les ampara el "derecho al desarrollo indígena y al control de los procesos de desarrollo en las regiones de asentamiento indígena", conforme a los mecanismos de participación previstos en la Ley de Gestión Ambiental. De igual manera, el Convenio reconoce las aspiraciones de los pueblos indígenas "a asumir el control de sus propias instituciones y formas de vida y de su desarrollo económico, y a mantener y fortalecer sus identidades, lenguas y religiones dentro del marco de los estados en los que viven".

Con relación al derecho de Consulta, el Convenio vela porque los pueblos indígenas que se encuentran dentro del área de influencia de una licitación de recursos no renovables, sean informados adecuadamente sobre el alcance del proyecto petrolero, expresen su opinión sobre este y lleguen a consensos con el Estado, en el marco del diálogo y la participación democrática.

El artículo 6 del Convenio 169 señala la política de aplicación de este instrumento internacional y las obligaciones gubernamentales que de él se desprenden:

4 Para una visión global de los alcances del Convenio 169, ver Gomes Magdatela 1995.

5 El Convenio 169 de la OIT fue reconocido por el Ministerio de Relaciones Exteriores del Ecuador en 1989, ratificado por el Congreso Nacional el 24 de Abril de 1998 y publicado en el Registro Oficial n²06 de junio de 1999. 
1. Al aplicar las disposiciones del presente Convenio, los gobiernos deberán:

a) Consultar a los pueblos interesados, mediante procedimientos apropiados y en particular a través de sus instituciones representativas, cada vez que se prevean medidas legislativas o administrativas susceptibles de afectarles directamente.

b) Establecer los medios a través de los cuales los pueblos interesados puedan participar libremente, por lo menos en la misma medida que otros sectores de la población, y a todos los niveles en la adopción de decisiones en instituciones electivas y organismos administrativos y de otra índole responsables de políticas y programas que les conciernan.

c) Establecer los medios para el pleno desarrollo de las instituciones e iniciativa de esos pueblos, y en los casos apropiados proporcionar los recursos necesarios para este fin.

2. Las consultas llevadas a cabo en aplicación de este Convenio deberán efectuarse de buena fe y de una manera apropiada a las circunstancias, con la finalidad de llegar a un acuerdo o lograr el consentimiento acerca de las medidas propuestas".

Si la consulta a las poblaciones locales es un derecho, su cumplimiento y promoción son responsabilidades que el Estado debe encargarse de cumplir y de hacer cumplir entre sus contratistas y los diferentes sectores de la sociedad civil. De hecho, la ausencia del Estado en algunas de las áreas en donde se manifiestan intereses contrapuestos, trae como resultado que las partes involucradas hayan tenido que encontrar frecuentemente sus propios mecanismos para la solución de sus conflictos. De ahí la necesidad de que el Estado desempeñe un rol más activo para asegurar un mejor balance entre las partes.

En este marco, es deber del Estado informar, capacitar y comunicar a los pueblos indígenas para que puedan decidir lo que más conviene a sus intereses, garantizando "procedimientos apropiados" para la consulta "a través de sus instituciones representativas", participando siempre que sea posible en los beneficios que reporten tales actividades y percibiendo una indemnización equitativa por cualquier daño que puedan sufrir como resultado de esas actividades (Convenio 169, Art. 15, \# 2; Constitución de la República, Art. 84, \# 5). Por otra parte, como dice el Art. 88 de la Constitución: "toda decisión estatal que pueda afectar al medio ambiente, deberá contar previamente con los criterios de la comunidad". 


\section{El Reglamento de consulta}

El "Reglamento de consulta y participación para la realización de actividades hidrocarburíferas", sancionado por el decreto 3401 de la Presidencia de la República (02.12.2002), es el mecanismo oficial que pretende garantizar el cumplimiento de este derecho a las poblaciones indígenas comprendidas en los proyectos hidrocarburíferos que podrían ser impulsados con participación de compañías transnacionales.

El Reglamento establece que la Consulta Prelicitatoria a los Pueblos Indígenas se realizará previa la convocatoria por parte del organismo encargado de llevar a cabo las licitaciones a los procesos licitatorios hidrocarburíferos (Título I, Cap. I, Art. 7). De acuerdo al Reglamento, esta Consulta Prelicitatoria a Pueblos y nacionalidades indígenas tiene por objeto:

a) Contar previamente con los criterios, comentarios, opiniones y propuestas de las nacionalidades indígenas que habiten en el área de influencia directa del bloque a licitarse relativos a los impactos socioambientales positivos y/o negativos que pueda causar en sus territorios la realización de los planes y programas que se desprendan de las licitaciones petroleras y de la suscripción de los correspondientes contratos de exploración y explotación.

b) Recibir criterios sobre las estrategias y medidas socioambientales generales de prevención, mitigación, control, compensación y rehabilitación relativas a los impactos socio-ambientales negativos, así como de impulso a los impactos socio-ambientales positivos, que deberá considerar el organismo encargado de llevar a cabo las licitaciones en la realización de los procesos licitatorios petroleros, la adjudicación y suscripción de contratos y las actividades de control de ejecución de los mismos.

c) Contar con los criterios sobre los mecanismos de participación de las nacionalidades indígenas que habiten en el área de influencia directa del bloque a licitarse, a través de sus organizaciones representativas, en la ejecución de las medidas socio-ambientales de prevención, mitigación, compensación, control y rehabilitación relacionadas con los impactos socio-ambientales negativos, así como de impulso a los impactos socio-ambientales positivos que se causen en sus territorios a causa de la realización de las actividades hidrocarburíferas que se desprendan de las licitaciones petroleras y de la suscripción de los correspondientes 
contratos de exploración y explotación. La información que obtenga el organismo encargado de llevar a cabo las licitaciones de estas consultas podrá ser incluida en las bases de licitación y otras secciones aplicables de la documentación prelicitatoria.

d) Establecer consensos apropiados con el Estado respecto del alcance del proyecto petrolero en cuanto a sus aspectos ambientales y sociales.

Sin embargo, el proceso de elaboración del Reglamento ha sido controvertido y sigue siendo considerado por muchos un proceso inconcluso. También han sido señalados vacíos de distinta magnitud en el Reglamento. Además de eventuales fallas de procedimiento (no existía una Ley Previa que lo amparara), la crítica más persistente es la ambigüedad del Reglamento, ya que la consulta se reduce en la práctica a identificar los impactos y definir su manejo, sobre la base de una decisión previamente adoptada por el Estado. Aún cuando no se admita la posibilidad absoluta de veto por parte de las comunidades, una de las implicaciones del derecho constitucional de los pueblos indígenas a ser consultados, sería indagar su criterio respecto a la posibilidad de que se realicen o no actividades hidrocarburíferas ${ }^{6}$.

A lo largo del proceso de Diagnóstico (2002) y de Consulta (2003), los debates con los representantes de las comunidades sobre el Reglamento y sus alcances ocuparon un lugar central en el proceso. En general, se creó el consenso de que el Reglamento era el instrumento vigente, perspectiva ratificada por el CODENPE, quien cita el "Reglamento en vigencia" (Art. 25) al aprobar la base de datos elaborada por la UPS 7 . Sin embargo, el Reglamento debía ser complementado y realimentado desde la práctica, en la perspectiva de que los cambios realizados pudieran apoyar la discusión sobre una eventual reforma integral del Reglamento.

Los vacíos del Reglamento fueron complementados en distintas direcciones:

- Con relación a la consulta "a través de las instituciones representativas", se decantaron posibles ambigüedades, identificando y activando los distintos sistemas organizativos locales (Federaciones, Organizaciones de Segundo Grado, Parroquias, Comunidades; ver metodología), a fin de asegurar su participación y su toma 
de decisiones oportuna e informada. Esta aproximación exigía respetar los procedimientos de representación y delegación vigentes en las comunidades y organizaciones, en una suerte de 'sufragio universal diferido y delegado' (ver más adelante).

- En este marco, se definió un sistema de interlocución que permitiera hacer llegar la información y la capacitación a todos los niveles de las organizaciones, aunque con distintas intensidades en función del tiempo disponible, con temarios definidos conjuntamente a lo largo del proceso.

- Los instructivos para los Talleres-asamblea comunitarios incluyeron abiertamente la posibilidad de hacer un pronunciamiento en CONTRA o A FAVOR del petróleo.

- Adicionalmente, se recogieron y afinaron las propuestas preliminares formuladas por las comunidades durante los Talleres de Consulta de la fase de Diagnóstico (2002). Dichas propuestas, a ser activadas en caso de que se viabilizara el proceso petrolero, incluían los siguientes puntos, que fueron precisados durante la Consulta: (I) utilización de tecnologías y procesos 'limpios' por parte de las compañías; (II) establecimiento de un fondo para el desarrollo regional (fideicomiso), a manera de 'compensación estructural' a las poblaciones locales (5\% de las inversiones petroleras, más otros fondos que se pudieran levantar ante organismos internacionales); (III) respeto a las 'áreas sensibles' de la región (núcleos densos de naturaleza y cultura), además de las Reservas; (IV) criterios básicos del proceso de participación y vigilancia comunitaria, incluyendo códigos de conducta de las compañías petroleras.

Estas propuestas y procedimientos complementarios han sido recogidos en los distintos instrumentos utilizados a lo largo del proceso de consulta (ver más adelante).

\section{Metodología para la realización de la Consulta Previa}

De acuerdo al Reglamento, el tiempo previsto para la realización de la Consulta era entre 60 y 90 días. En la práctica, después de haber elaborado y consensuado con el Estado la metodología de consulta (junio julio, a tiempo parcial), el equipo de la UPS inició las tareas de preparación del proceso durante el mes de agosto (organizaron los equipos). 
Durante las 3 primeras semanas de septiembre tuvieron lugar reuniones con las distintas Federaciones y Parroquias, con la finalidad de crear consensos y preparar el proceso de Consulta. Entre el 22 de septiembre y el 15 de diciembre (12 semanas) se desarrollaron las actividades relacionadas con la capacitación, la comunicación, los pronunciamientos comunitarios, la notarización de las Actas comunales e intercomunales y la elaboración de propuestas.

En general, las actividades realizadas durante el proceso de Consulta han sido las siguientes:

- Identificar las comunidades que participarán en la Consulta Previa y establecer con las organizaciones locales consensos apropiados tendientes a su participación.

- Definir y aplicar parámetros apropiados de participación y pronunciamiento de las comunidades, rescatando y complementando los procedimientos tradicionales, para asegurar una participación representativa en la Consulta.

- Capacitar a los líderes y representantes comunitarios mediante la celebración de talleres y la elaboración de materiales 'ad hoc'.

- Comunicar y difundir oportuna y apropiadamente, a través de los medios de comunicación locales y nacionales, los contenidos relativos a los derechos de las poblaciones indígenas con relación a la Consulta Previa, así como a las oportunidades y riesgos del proceso de exploración y explotación petrolera.

- Recabar los criterios, opiniones y propuestas de las comunidades y sus representantes legítimos a propósito del proceso petrolero.

- Supervisar y realimentar permanentemente el proceso de realización de la Consulta Previa (monitoreo interno a cargo de los representantes de las comunidades; participación abierta a las instituciones consideradas por el Reglamento: Ministerio del Ambiente, CEDENMA, CONFENIAE, CONAIE, CODENPE).

- Sistematizar y elaborar una memoria técnica del proceso.

\section{Identificación de las organizaciones interlocutoras}

La primera exigencia de la consulta previa era que el pronunciamiento de las comunidades fuera libre e informado. En otras palabras, 
debía existir un proceso previo de información y capacitación en el que se explicara el alcance de los derechos colectivos con relación a la Consulta Previa, los riesgos y oportunidades del proceso petrolero, los procedimientos de compensación e indemnización (en caso de ser viable el proceso petrolero), y las medidas de prevención y mitigación de los eventuales impactos socio-ambientales. Este conjunto de componentes se constituyó en referente de la propuesta de capacitación (ver más adelante).

Sin embargo, el Convenio 169 y el Reglamento de Consulta proponen que los Pueblos Indígenas sean interpelados a través de sus 'organizaciones representativas'. En este sentido, era fundamental proceder a la identificación de las organizaciones indígenas del área de los bloques, especificando su nivel de representatividad y sus relaciones mutuas. Para ello, se elaboró una base de datos, sucesivamente revisada y ajustada, que permitió identificar 379 comunidades en el área de los bloques, distribuidas entre nueve (9) Federaciones y catorce (14) Parroquias con población dentro del área; también fueron identificadas cinco (5) Organizaciones de Segundo Grado, adscritas a la Federación más grande (Federación de Organizaciones y Nacionalidades Kichwas de Napo FONAKIN).

De esta forma, se establecieron dos referentes básicos de interlocución :

- Federaciones Indígenas para las comunidades federadas, incluyendo niveles crecientes de complejidad, como es el caso de las OSGs.

- Parroquias para las comunidades no federadas.

Un proceso de esta naturaleza debía permitir la participación directa de la mayoría de la población indígena en la toma de decisiones. Sin embargo, el carácter electivo, representativo y delegado del sistema democrático no suele garantizar suficientemente esta participación .

8 Las organizaciones indigenas de carácter 'funcional' (productivo, ecoturístico, etc.) no fueron consideradas como interlocutores directos, por cuanto sus miembros pertenecian simultáneamente a una de las comunidades adscritas a federaciones o parroquias, desde las que fueron convocadas.

9 cf. Albán 2003. 
En lugar de diseñar una metodología que localizara la consulta en los niveles superiores e intermedios de las organizaciones (dirigentes o presidentes de comunidades, en el mejor de los casos), se optó por una metodología más compleja, que permitiera alcanzar también al máximo número de comunidades de base, de manera que la mayoría estuviera lo suficientemente informada como para poder pronunciarse a propósito del proceso petrolero. Si bien era una metodología exigente, considerando las características del proceso y el tiempo disponible, los resultados obtenidos avalan la decisión adoptada. Por otra parte, se trataba de un proceso ya iniciado durante el 2002, a raíz de la realización del Diagnóstico Participativo y de la elaboración de propuestas metodológicas complementarias para la futura consulta mediante talleres participativos por subzonas (Ahuano, Santa Clara, San Pablo, Misahuallí, 24 de Mayo).

En este marco, una vez identificadas las organizaciones locales, se decidió interpelar a cada uno de los niveles organizativos existente, en una dinámica que ha permitido recorrer el camino 'de arriba hacia abajo y de abajo hacia arriba' de las organizaciones:

- Selección de facilitadores por parte de sus respectivas Federaciones, OSGs o Parroquias, para su capacitación por parte del equipo de la UPS. De hecho, el Reglamento de Consulta aconseja la participación de 'técnicos indígenas' como facilitadores. En esta dirección, se debía proceder a la especificación del $\mathrm{n}^{\circ}$ de facilitadores por organización representativa, sobre una base de proporcionalidad que fue discutida y consensuada con los Presidentes de Federaciones y Parroquias.

- Realización de Talleres intercomunales de capacitación de 2 a 3 días de duración (2.5 días en promedio), con delegados de cada comunidad.

- Realización de Talleres-Asambleas Comunales de un día en cada comunidad (información en la primera parte y toma de decisiones transcritas en Actas durante la segunda). Las comunidades, debidamente convocadas e interpeladas por los dirigentes de los distintos niveles organizativos (Federaciones y Parroquias), constituyen el espacio que legitima todo el proceso organizativo; en esta dirección, debían ser también el espacio fundamental de pronunciamiento sobre el petróleo.

- Realización de Asambleas Intercomunales de un día de duración, como instancia de validación de las Asambleas comunales y de la dinámica comunitaria.

- Reuniones periódicas con presidentes de Federaciones y Parroquias para acompañar y realimentar el proceso de Consulta. 


\section{Información, capacitación y pronunciamientos}

Por otra parte, debía diferenciarse cuidadosamente los espacios de información y capacitación de los espacios de pronunciamiento y toma de decisiones informada:

- además del contenido informativo de la creación de capacidades, la información fue proporcionada a través de materiales impresos, vídeos y cuñas radiales, que sirvieron de soporte a la capacitación y a la toma de decisiones;

- la capacitación fue impartida en talleres a distintos niveles:

* el nivel de mayor intensidad se dio con el equipo de 32 facilitadores (11 días de talleres, más 4 días adicionales de revisión y realimentación constante del proceso desde la práctica);

* el segundo, en 9 talleres intercomunales con alrededor de 400 delegados de la mayoría de las comunidades (3 días de reuniones por taller, con un promedio de 45 participantes);

* el tercero, en 337 talleres realizados en otras tantas comunidades (el $89 \%$ del total), que convocaron a más de 9000 personas (medio día de información, acompañada por el presidente o delegado que asistió a los talleres intercomunales, más el facilitador);

- la toma de decisiones se dio en tres momentos:

* durante la segunda parte de cada taller comunitario, transformado en asamblea extraordinaria de la comunidad, sin la presencia de facilitadores (pronunciamiento de alrededor de 9000 personas);

* también cumplieron esa función las asambleas intercomunales, como instancia de validación del proceso de participación comunitaria (participación de 229 presidentes de comunidades);

* finalmente, todo el proceso de participación y consulta fue ratificado por el 'Comité de la nacionalidad kichwa de los bloques 20 y 29', que prolonga e institucionaliza las reuniones semanales de los presidentes de 9 federaciones y 14 juntas parroquiales ( 23 personas en promedio), encargados de dar seguimiento a la Consulta (ver más adelante).

De esta manera, se ha tratado de un proceso de aproximaciones sucesivas a las organizaciones y comunidades, combinando distintos niveles de toma de decisiones, en una dinámica de mutua realimentación. 


\section{Aprobación y revisión de las bases de datos de las organizaciones y comunidades}

Con anterioridad al inicio de las actividades, y como condición para el arranque de las mismas conforme al Reglamento de Consulta, el Consejo de Desarrollo de las Nacionalidades y Pueblos del Ecuador CODENPE, en Oficio 105 SD del 25 de agosto del 2003, certificó la base de datos de las organizaciones elaborada a raíz del Diagnóstico realizado en el 2002 e integrada por 484, comunidades adscritas a distintas Federaciones y Parroquias. El CODENPE sugirió algunos cambios en el caso de 8 comunidades que habían cambiado de jurisdicción durante el tiempo transcurrido entre el Diagnóstico y la Consulta.

Estas bases fueron revisadas posteriormente con los facilitadores delegados de las organizaciones y ajustadas en consecuencia. La base de datos final depurada está constituida por 379 comunidades. El proceso de ajuste obedecía a las siguientes razones:

faltaban nuevas comunidades de la provincia de Orellana (parroquias Dahuano, Waticocha y Ávila Huiruno) y de otras Federaciones no adscritas a la CONAIE, como AMA (Arajuno - Pastaza);

- en la base inicial estaban incluidas algunas organizaciones (8) conformadas exclusivamente por colonos, que no podían ser incluidas formalmente en el proceso de consulta previa, orientado -conforme al Reglamento de Consulta- a los pueblos indígenas de la región o a comunidades mixtas (indígenas y colonos);

- en Tena y Archidona estaban registradas organizaciones barriales o gremiales conformadas por indígenas que estaban ya adscritos a una determinada comunidad, por lo que se estaba duplicando la convocatoria;

- algunas organizaciones habían cambiado de nombre, se habían fundido con otras o habían aparecido recientemente;

- una parte significativa de las organizaciones que habían sido registradas en las parroquias Ahuano y Chontapunta pertenecían, en realidad, al bloque 21, por lo que tenían que ser excluidas de las bases de datos; de hecho, el $29.5 \%$ y el $98.6 \%$ del territorio de cada una de las parroquias, respectivamente, estaban fuera de los bloques.

El proceso de Diagnóstico permitió identificar la existencia de federaciones indígenas adicionales a la FONAKIN, adscrita a la CONAIE; estas 
federaciones eran ignoradas usualmente por el Estado y por la mayoría de las instituciones de apoyo (ver nota $\mathrm{n}^{\circ} 6$ ).

\title{
Reuniones previas con las Organizaciones para definir consensos
}

Como preparación de la Consulta, entre fines de agosto y fines de septiembre del 2003 se realizaron quince reuniones con representantes de las principales Federaciones y Parroquias del área de los bloques, a fin de concordar la factibilidad y modalidades de realización de la Consulta. Se mantuvieron reuniones a distintos niveles con directivos y presidentes de OSGs, y asambleas ampliadas con miembros de las comunidades ${ }^{10}$. Los objetivos de las reuniones y asambleas eran los siguientes: (I) explicar los antecedentes de la Consulta Previa (Diagnóstico Participativo y Talleres Comunitarios -septiembre a diciembre del 2002), retomando los contactos desde la última reunión de febrero del 2003 (devolución de resultados de la Consultoría, realizada a través de la FONAKIN); (II) revisar y completar la base de datos de las organizaciones; (III) justificar las relaciones existentes entre la Propuesta de Consulta Previa y las conclusiones y recomendaciones del Diagnóstico Participativo y de los Talleres zonales (septiembrediciembre del 2002); (IV) exponer y debatir la propuesta de Consulta (información, capacitación, Asambleas de pronunciamiento), y discutir tópicos relacionados con el Reglamento de Consulta; (V) solicitar los avales correspondientes para iniciar la organización del proceso de Consulta. Los presidentes de la CONFENIAE y del Parlamento Amazónico participaron también activamente en una reunión con representantes de las Organizaciones de Segundo Grado y Presidentes de Juntas Parroquiales afines a la FONAKIN.

Tras estas reuniones y asambleas ampliadas, se creó consenso acerca de la conveniencia de dar inicio al proceso de información, capacitación y -al final del mismo- de Consulta formal, así como acerca de la

\begin{abstract}
10 Las reuniones mantenidas convocaron a los presidentes, directivos y miembros de base de las siguientes instituciones: Federaciones y OSGs Indigenas de las tres provincias (Napo: FONAKIN, adscrita a la CONAIE; FOCIN, FAOICIN, FICEN y FEKAN, adscritas al GOFOKIN; Pastaza: ANKISC y ACIA, adscritas a la OPIP y a la CONAIE; AMA y Ayllu Pura, independientes; Orellana: FEPKIL, adscrita a la FONAKN y a la CONAIE), y Juntas Parroquiales de la provincia del Napo. En el caso de la FONAKIN, también tuvo lugar una reunión de consenso preliminar en las Asamblea Extraordinaria de Mondayaku, con la participación de más de 300 personas de un gran número de comunidades.
\end{abstract}


metodología y los instrumentos necesarios para llevar a cabo dicho proceso (selección del equipo de facilitadores, delegados directamente de las Federaciones y Juntas Parroquiales; organización de talleres con representantes de las organizaciones y comunidades; realización de asambleas comunales e intercomunales).

\section{Convocatoria a la Consulta y apertura de las Oficinas de Consulta}

Una vez alcanzados consensos básicos acerca del inicio del proceso de Consulta, se procedió a publicar la Convocatoria en la prensa.

El Reglamento (Título III, Cap. 1, art. 23) prescribe que "la convocatoria deberá hacerse mediante dos publicaciones en días consecutivos en dos periódicos de mayor circulación nacional y, de ser posible, en un periódico local de la circunscripción territorial correspondiente al área a ser licitada, así como mediante cuñas radiales en el área correspondiente al bloque a licitarse y a través de otros medios de comunicación disponibles que aseguren una efectiva difusión de la convocatoria. La convocatoria fue realizada en kichwa y castellano (El Comercio, El Hoy, 18 radios) y contenía la siguiente información:

a) Identificación del bloque, denominación del área y ubicación geográfica

b) Objeto de la consulta

c) Mención general de las fases de la actividad hidrocarburífera que se llevarán a cabo

d) Mención general del marco regulatorio que rige el proceso de consulta previa

e) Cronograma y ubicación del proceso de Consulta, así como instrumentos de consulta a aplicar

f) Ubicación de la Oficina de Consulta, período y horario de atención. Las oficinas de consulta, una por bloque, fueron localizadas en Ahuano (bloque 29) y en Archidona (bloque 29).

Simultáneamente, se procedió a habilitar dos Oficinas de Consulta, una por bloque. La función de estas oficinas ha sido, como prescribe el Reglamento, informar a la ciudadanía en general acera del alcance del proceso de Consulta, colaborar en el proceso de organización de la Consulta, recabar eventuales opiniones de la ciudadanía en general y 
procesar los aspectos formales de los pronunciamientos de las organizaciones representativas de las comunidades indígenas ${ }^{11}$.

\section{Reuniones de organización y acompañamiento del proceso}

Todo el proceso fue diseñado y organizado conjuntamente con 23 representantes de las 9 Federaciones y 14 Juntas Parroquiales participantes. Para este fin, además de las reuniones preparatorias, han sido mantenidas reuniones permanentes en los siguientes escenarios:

(I) inauguración de las Oficinas de Consulta;

(II) reuniones de supervisión del proceso de capacitación (facilitadores y talleres intercomunales);

(III) reuniones semanales para programar, validar el proceso de Consulta y adoptar decisiones conjuntas. Además de la organización y convocatoria conjunta de los eventos, se revisaron y concordaron los instructivos para la realización de Asambleas (comunales e intercomunales).

(IV) También se emitieron distintos comunicados, entre ellos una carta de pronunciamiento colectivo del grupo, suscrita por todos los presidentes de Federaciones y Parroquias, para desautorizar los intentos de desinformación y desestabilización del proceso de Consulta por parte de algunos grupos 'ecologistas'.

Adicionalmente, se ha mantenido en Quito reuniones semanales al inicio y quincenales después con Petroecuador y el Ministerio de Energía y Minas, para coordinar el inicio de la Consulta e informar sobre el desarrollo del proceso. De igual manera, se ha organizado y realizado 6 visitas a la zona en distintos momentos del proceso, tanto con personeros de Petroecuador como del MEM, encargado oficial del seguimiento al proceso. A raíz de

11 Como ya ha sido explicado, la Consulta pretende dar cumplimiento al Convenio 169 de la OIT, cuyos sujetos son los pueblos indígenas originarios del lugar donde se piensa llevar cabo procesos de explotación de recursos no renovables como el petróleo, además de comunidades mixtas (indígenas y colonos); el resto de la ciudadanía (habitantes rurales no indigenas, ONGs, habitantes urbanos) ha sido informado a través de la permanente difusión realizada mediante programas radiales y distribución focalizada de material impreso, además del material disponible en las Oficinas de Consulta, donde podían dejar constancia escrita de sus criterios sobre el petróleo. 
la culminación del proceso de Consulta, se realizó también una visita de inspección final al área de los bloques por parte de funcionarios del Ministerio y de Petroecuador, y se procedió a clausurar formalmente las Oficinas de Consulta. Además de visitar las Oficinas y conversar con el equipo de la UPS y con los facilitadotes, los funcionarios participaron en la reunión semanal de Presidentes de Federaciones y Juntas Parroquiales (que contó con la presencia del Presidente del Parlamento Amazónico de la CONFENIAE), donde expusieron sus puntos de vista y respondieron a las preguntas de los participantes.

\section{Monitoreo, evaluación y seguimiento}

Un elemento clave de la Consulta fue la evaluación y monitoreo permanentes, que ha permitido realimentar el proceso y hacer correcciones sobre la marcha para obtener mejores resultados en cada uno de los eventos. Sus resultados son analizados más adelante. Para realizar esta evaluación se ha contado con varios instrumentos:

a. Formulario de evaluación entregado a cada uno de los participantes luego de cada evento (con excepción de los dos primeros talleres, que sirvieron para validar los instrumentos a ser utilizados).

b. Grupos focales y entrevistas colectivas con los facilitadotes.

c. Entrevistas informales a los participantes.

Por encima del equipo de la UPS, el seguimiento del proceso estuvo en manos del grupo de Presidentes de Federaciones y Parroquias. Además de tareas relacionadas con la programación sus funciones básicas fueron revisar permanentemente los resultados que se iban alcanzando, para realimentarlos desde el proceso mismo de ejecución, y validar el proceso de Consulta.

También se preveía la intervención de observadores externos. Además de funcionarios del Ministerio de Energía y Minas y de Petroecuador, el Reglamento posibilita la participación de otras instancias del Estado (Ministerio del Ambiente, CODENPE), de las instituciones representativas de los pueblos indígenas (CONFENIAE, CONAIE, etc.) y del CEDENMA, que integra a la mayoría de las organizaciones ambientalistas. Además del CODENPE (quien avaló las bases de datos 
y el arranque del proceso de Consulta), participaron activamente representantes de la CONFENIAE, en particular, el Presidente del Parlamento Amazónico, quien se integró en forma semipermanente a las reuniones del grupo de Presidentes de Federaciones y Parroquias.

Finalmente, se elaboraron distintos organigramas y un cronograma del proceso (talleres y asambleas), que ha ido siendo ajustado en función de la evolución real de los acontecimientos.

\section{Comunicación y capacitación}

\section{Comunicación}

Durante el proceso de preparación y ejecución de la Consulta, se elaboró y distribuyó distintos materiales de comunicación, que apoyaron permanentemente el proceso.

Los materiales elaborados y distribuidos han sido los siguientes:

- Tres mil cartillas de Consulta a colores (10 páginas en kichwa y otras 10 en castellano), elaboradas y validadas conjuntamente con los encargados de comunicación de las organizaciones indígenas. En ellas se resume de manera crítica el rol del petróleo en la región y en la economía nacional, se resume el diagnóstico de los bloques y se señalan las principales implicaciones de un ejercicio apropiado de los derechos colectivos. En la portada de las cartillas figura un texto sugerido directamente por el grupo de comunicadores indígenas en el 2002 ("Ayer decidieron nuestro presente, hoy damos los primeros pasos para decidir nuestro futuro"), que aparece también en las pancartas

- Pancartas, CDs y vídeo (kichwa - castellano), que sintetizan los principales temas relacionados con la Consulta y el proceso petrolero. Los CDs sirvieron de referencia para la difusión de tres bloques informativos sobre la Consulta y el proceso petrolero, a través de las cuatro radios de mayor frecuencia de la región (dos en Tena y otras dos en Puyo). Las pancartas fueron colocadas en lugares estratégicos.

- Mil doscientos folletos de capacitación (22 páginas), cuya finalidad fue la de apoyar la capacitación de los facilitadores, los delegados de las comunidades y los presidentes de Federaciones y Parroquias. Los folletos han sido validados con los facilitadores comunitarios e incluyen los principales temas relacionados con el proceso de Consulta (ver 
capacitación). Al nivel de contenidos, este folleto ha constituido el referente del proceso de capacitación, junto con la elaboración de resúmenes verbales o escritos y papelotes.

Los espacios de distribución de los materiales impresos y del vídeo han sido las Federaciones y Juntas Parroquiales, los talleres intercomunales de capacitación y los talleres comunitarios; también han sido distribuidos entre instituciones de la sociedad civil (educación bilingüe e intercultural, ONGs, etc.).

\section{Capacitación}

\section{Contenidos}

Los contenidos elaborados para el proceso de capacitación han sido el resultado de distintas investigaciones por parte del equipo consultor acerca de la temática petrolera, los derechos colectivos, participación y control social, compensaciones e indemnizaciones, áreas sensibles y comunicación. Estos contenidos han sido compartidos y validados, en forma sucesiva, algunos con el grupo de comunicadores (2002) y otros con el de facilitadores y presidentes (2003).

El referente para la elaboración de los contenidos han sido las necesidades de capacitación de los diferentes integrantes de las comunidades, sus dirigentes y organizaciones (conforme a las demandas formuladas en los Talleres de Consulta del 2002), complementadas por otros aspectos que debían ser conocidos por los participantes de este proceso, con la finalidad de que su decisión fuera absolutamente informada y consciente.

Además de información general sobre el proceso, los contenidos de los folletos de capacitación abordan los siguientes temas:

- Derechos, responsabilidades, participación y vigilancia social: las bases de la consulta previa.

- Consulta previa (características, desarrollo). 
- El petróleo: riesgos y oportunidades ${ }^{12}$.

- Indemnizaciones y compensaciones para el desarrollo regional (ver más adelante en "Propuestas").

- Áreas sensibles (naturaleza y cultura). Se trata de lugares sagrados y sitios de importancia ecológica, adicionales a los Parques y Reservas, que fueron identificados preliminarmente por los participantes y por cada comunidad en los talleres (petroglifos, lugares shamánicos, etc.).

12 Por tratarse de uno de los temas más cuestionados, resumimos aqui el contenido del folleto de capacitación con relación al petróleo. El petróleo es descrito como uno de los principales recursos energéticos, aunque escaso, limitado y contaminante; un recurso que ha contribuido substancialmente al financiamiento del presupuesto del Estado, aunque no ha sido bien invertido en la dinamización del aparato productivo y se ha incrementado considerablemente la deuda externa. Con relación a la Amazonia, las rentas petroleras se han distribuido con un criterio centralista, de reparto desigual y de discriminación regional. Por eso, la historia del petróleo en la Amazonia ha sido en buena medida una historia de alteración de hábitats naturales y formas de vida, asi como de daños en la salud y en las propias relaciones comunitarias y familiares. El folleto incorpora expresiones como "colonización descontrolada", "destrucción o contaminación", "etnocidio", "conflictos y violación de derechos", "desarticulación de formas de organización local"... Se nombran también los problemas pendientes: (I) débil adopción de métodos modernos de conservación del ambiente, mitigación de los impactos ambientales negativos, mecanismos de monitoreo y control...; (II) ausencia de mecanismos y procedimientos claros y eficientes de indemnización y compensación; (III) falta de visión clara y consciente de las dimensiones sociales, demográficas y culturales; (IV) imprecisiones, desinformación e incomprensión de los procesos globales en los debates petroleros, sesgados hacia visiones e intereses particulares y posiciones que impiden construir propuestas alternativas de aprovechamiento de este recurso, de forma más equitativa y sostenible. También se describe el importante avance logrado al nivel legislativo durante las últimas décadas.

En cuanto a las tecnologías, se describe minuciosamente los "impactos en el ambiente y la cultura" a propósito de cada una de las fases del proceso petrolero, se habla de las nuevas tecnologías y se nombran experiencias parcialmente exitosas de control y mitigación de daños ambientales. Finalmente, se analiza los principales desafíos para la región amazónica, concluyendo que el problema de la gestión socio-ambiental es fundamentalmente político y organizativo, no solo técnico. 
El folleto resume sus características e importancia y concluye la necesidad de que sean respetadas.

\section{Modalidades}

En cuanto a las modalidades, como hemos señalado, la capacitación fue impartida a distintos niveles: facilitadores, talleres intercomunales con presidentes de comunidades y talleres con las comunidades.

El primer nivel de capacitación se relaciona con los facilitadores comunitarios. Como hemos anticipado, los facilitadores fueron seleccionados directamente por las federaciones y parroquias. La mayoría de ellos habían estado vinculados a procesos de capacitación formal y habían desempeñado cargos en sus organizaciones; por otra parte, más allá de sus posiciones personales, debían ser capaces de orientar las decisiones de las comunidades, exponiéndolas tanto a los aspectos negativos cuanto a los potencialmente 'positivos' del petróleo.

Durante el proceso de formación de facilitadores se enfatizaron los aspectos metodológicos vinculados al desarrollo de destrezas para aprender y enseñar, y se manejaron los principales conocimientos formales relacionados con la Consulta, incluidos en el folleto de capacitación, a través de modalidades de formación presencial y semi-presencial. Además de los 11 días de capacitación formal, durante el desarrollo de los talleres y asambleas se realizaron también jornadas de evaluación y refuerzo temático.

El segundo nivel fue la capacitación de los delegados comunitarios en talleres intercomunales. Por un lado, había que adecuar los contenidos (derechos colectivos, consulta previa, riesgos y oportunidades de la explotación petrolera, áreas sensibles y compensaciones e indemnizaciones) a la capacidad de comprensión de los participantes, mediante la preparación de guías y exposiciones en 'power point', resúmenes en papelotes, etc., entrenando a los facilitadores en su manejo interactivo; por otro lado, era necesario pensar en todos los aspectos operativos (fechas y convocatorias, materiales, locales, alimentación, movilización, alojamiento, equipos, material de consulta...) e intentar que el tiempo disponible, las distancias, la composición de los participantes, la naturaleza del tema y los permanentes ataques de opositores a la Consulta no conspiraran demasiado en contra de la dinámica planificada.

$\mathrm{Al}$ inicio (2 primeros talleres), el equipo de la UPS se encargó de los temas principales, con la colaboración de los facilitadores (trabajo de 
grupos, etc.). Sin embargo, a partir del tercer taller los facilitadores se fueron haciendo cargo de la exposición en lengua kichwa, con apoyo del equipo de la UPS en el debate, adquiriendo, paulatinamente, más y mejores destrezas expositivas y de comunicación con la gente, a través de la asunción progresiva de responsabilidades. A pesar de algunas dudas iniciales en el manejo de contenidos, el uso de la propia lengua elevó notablemente la participación de los delegados de las comunidades. Una vez evaluados los dos primeros talleres (Tena y Mondayacu), se procedió a conformar dos grupos de facilitadores, de acuerdo a criterios como la pertenencia geográfica de los facilitadores, y sus habilidades y destrezas para apoyar tareas de exposición, animación, etc.

Con el fin de consolidar los conocimientos y el trabajo de los delegados comunitarios en sus comunidades, los técnicos de capacitación y comunicación reforzaron la parte relacionada con la manera de llevar a cabo un taller asamblea, mediante varios ejemplos y simulaciones.

En total, estos talleres convocaron a 360 participantes y 59 observadores de las comunidades, Federaciones o Confederaciones.

El tercer nivel fueron los Talleres - Asamblea comunitarios, el espacio de las comunidades, que se decidió alcanzar directamente para posibilitar el pronunciamiento de la mayoría. Durante la primera parte del taller (alrededor de 5 horas), los miembros de la comunidad recibieron información sobre los diversos temas relativos a la consulta previa (derechos, consulta, riesgos y oportunidades, etc.). Posteriormente se dio paso a preguntas y respuestas, aclaraciones y ampliaciones de algunos de los aspectos presentados. Durante la segunda parte, el taller se trasformó en asamblea y los miembros de cada comunidad, acompañados por los dirigentes que asistieron a los talleres de capacitación, deliberaron sobre los temas abordados y adoptaron sus propias resoluciones (ver más adelante). Estos talleres estuvieron precedidos y acompañados por los talleres de consulta (2002), y la difusión de cuñas radiales, cartillas y folletos; adicionalmente, los delegados de las comunidades fueron capacitados durante tres días sobre la forma de compartir con sus comunidades los conocimientos adquiridos, por lo que una buena parte de los integrantes de cada comunidad había sido ya expuesto previamente la información sobre el tema petrolero y la Consulta previa. Cada delegado comunitario, con la información proporcionada en los talleres intercomunales, elaboró un resumen en papelote, con el fin de que este le sir- 
viera de guía en la entrega de la información a su comunidad. Este trabajo fue apoyado por el facilitador respectivo.

La asignación de los facilitadores fue realizada conforme al lugar de procedencia y a su pertenencia a una organización de base, de segundo grado, Federación o Junta Parroquial, lo que facilitó el buen desarrollo de los Talleres-Asamblea; por otra parte, el hecho de ser de la zona hizo que las resistencias de los miembros de las comunidades fueron casi nulas, salvo las excepciones que puede suscitar un tema tan controversial como es el desarrollo de procesos de explotación petrolera.

\title{
Resultados alcanzados
}

Las evaluaciones por parte de los facilitadores subrayan su satisfacción con los contenidos y organización de la capacitación; así, el 97.4\% opina que la capacitación fue buena o muy buena. Cabe destacar que de un promedio grupal inicial de $3 / 10$, los participantes autoevaluaron públicamente sus conocimientos con un 6.4/10, lo que implica más del doble de aprendizaje en los temas propuestos e incrementos sustanciales, especialmente en los temas de Compensaciones y Consulta Previa, así como en las calificaciones individuales, cuyos valores mínimo y máximo pasaron de $1 / 5$ al inicio a 5/9 al final, respectivamente. Las calificaciones objetivas demostraron igualmente que todos los participantes demostraban un buen nivel de conocimientos generales con relación a la temática $^{13}$. No obstante, la mayoría de los facilitadores señalaron temas

\begin{abstract}
13 Con relación a los resultados finales de la Consulta (favorables al inicio de un proceso petrolero 'condicionado'-ver más adelante), es interesante constatar que, de acuerdo a las evaluaciones de los conocimientos adquiridos, los facilitadores estaban en condiciones de precisar mucho mejor los riesgos/amenazas del petróleo que las oportunidades. Esta relativa mayor capacidad de dar cuenta de los aspectos negativos es atribuible a los siguientes factores: (I) el énfasis de los Talleres de Consulta (UPS, 2002) en los riesgos y daños socioambientales causados por el petróleo; (II) la información contra el petróleo por parte de grupos opuestos al proceso petrolero y a la Consulta misma, difundida permanentemente a través de los medios de comunicación locales, y realimentada por la situación de Sucumbios (juicio a la Texaco) y de Sarayaku.
\end{abstract}


de capacitación que necesitaban ser ampliados y dieron sugerencias para mejorar los materiales y la organización de los eventos ${ }^{14}$.

El balance general de los talleres de delegados a los talleres intercomunales ha sido altamente positivo, tanto con relación a los contenidos, como a las exposiciones, la organización y el taller en general. De acuerdo a los cuestionarios administrados entre los participantes, el $98.25 \%$ estimaron que los talleres habían sido buenos o muy buenos, oscilando entre el $100 \%$ en cuanto a contenidos y el $92.75 \%$ en cuanto a organización. No obstante, los participantes formularon sugerencias relacionadas con la realización de talleres adicionales de capacitación, sobre todo en las comunidades, que involucraran también a las mujeres; la entrega oportuna de materiales, la mayor claridad en las exposiciones, la capacitación adicional de los facilitadores, la mejor coordinación con las bases y la mejor organización de las comunidades. También cabe señalar la existencia de ritmos y capacidades diferentes en los facilitadores.

El logro más importante ha sido la participación activa de la mayoría de delegados de las comunidades, lo que posibilitó su posterior conducción de las asambleas comunitarias. Adicionalmente, en la mayoría de los Talleres los participantes decidieron elaborar Actas de recomendaciones, que orientaran el posterior trabajo de las comunidades ${ }^{15}$.

En cuanto a los talleres comunales, en general los facilitadores han sido bien recibidos, y la mayoría de la gente ha aceptado y entendido sus explicaciones, solicitándoles toda la información posible. La capacitación confirmó la necesidad de actuar sobre la base de información y argumentos ciertos, lo que ha permitido manejar las posiciones extremas de algunos actores; de hecho, los delegados comunales presentes en los talleres intercomunitarios han sido quienes han sostenido, en gran parte, el desarrollo de los talleres - asamblea y la toma de posición final.

\footnotetext{
14 Muchos de los temas fueron abordados de nuevo a raíz de la revisión conjunta del proceso y de sus resultados. No obstante, el pedido formal de ampliación de la capacitación está en proceso de ser atendido en el período post-consulta, a través de la profundización de la temática petrolera y de la creación de condiciones apropiadas de participación en el proceso de exploración y explotación hidrocarburifera.
}

15 Algunas Actas (como la de 24 de Mayo - Orellana) fueron transmitidas por la radio local, como un ejemplo de acuerdo entre las organizaciones y como el ejercicio de un derecho ciudadano. 
Al igual que en los demás talleres, los participantes formularon sugerencias relacionadas con la realización de talleres similares sobre los mismos temas y sobre otros temas de interés comunitario, con apoyo de folletos y documentos; también pidieron mayor tiempo para el tratamiento de los temas, para el trabajo de grupos y para el análisis en plenaria.

En general, la demanda por momentos de capacitación e información adicionales ha sido compatible con la sensación de haber recibido una información lo suficientemente pertinente y apropiada como para posibilitar un pronunciamiento.

\section{Los pronunciamientos de las comunidades}

Analizaremos a continuación los resultados de los pronunciamientos de las comunidades y organizaciones del área de los bloques acerca del proceso petrolero. Para poder calibrar apropiadamente su alcance, los pronunciamientos son considerados en el marco socio-organizativo en el que fueron pronunciados.

\section{Las asambleas comunitarias}

\section{Programación y características}

Una de las actividades fundamentales del proceso de consulta previa han sido los talleres-asambleas al nivel de cada comunidad, cuya realización apropiada exigió una organización sumamente prolija para lograr los objetivos de participación trazados. Además de los factores externos (incesantes ataques de grupos fundamentalistas opuestos a la Consulta), la programación debía tener en cuenta factores como la cantidad de comunidades a cargo de cada facilitador (entre 15 y 18), la entrega oportuna de convocatorias, la disponibilidad de tiempo de los dirigentes comunitarios y de los miembros de la comunidad, la consideración de divisiones y disputas al interior de las comunidades, el acceso a las comunidades (vial y fluvial), la disponibilidad de refrigerios en cada comunidad, etc.

En este espacio, como hemos señalado, los miembros de las comunidades han recibido en una primera parte (el taller) la información 
necesaria sobre los diversos temas contenidos en la consulta previa, a través de los delegados que participaron en los talleres intercomunales de capacitación, apoyados por los facilitadores. Durante la segunda parte (alrededor de 5 horas), los participantes se han instalado en asamblea extraordinaria, han deliberado sobre los temas abordados y han tomado las resoluciones más pertinentes respecto a la conveniencia o no de que se lleven a cabo actividades de explotación hidrocarburífera en su territorio.

Con la finalidad de que los talleres-asambleas se desarrollaran de acuerdo a lo previsto, los presidentes de las Federaciones y Parroquias, junto con los facilitadores y con el apoyo del equipo técnico de la UPS, creyeron necesario que se diseñara una propuesta de instructivo para el desarrollo de las reuniones. Dicho instructivo desarrollaba los aspectos formales de las asambleas, es decir, convocatorias, participaciones, horarios, constitución de la asamblea y su legalidad, sugerencia de formatos para capturar los pronunciamientos, etc. En este instructivo constaba expresamente la posibilidad de pronunciarse contra del petróleo, en caso de que los riesgos parecieran incontrolables o fueran más grandes que las oportunidades.

\section{Desarrollo de los talleres - asamblea}

En la totalidad de los talleres-asambleas se recurrió al mismo tipo de procedimientos, ya que la práctica parlamentaria es conocida por todos los presidentes y miembros de las comunidades. En este caso especial, los presidentes de las comunidades resaltaron el hecho histórico de que por primera vez habían sido tomados en cuenta y convocados para ser capacitados y consultados sobre un asunto de vital importancia para la vida de las comunidades.

En el momento de instalación de la asamblea extraordinaria por parte de los dirigentes de la comunidad, se procedió a constatar la existencia de quórum; posteriormente, se inició el análisis y la discusión de los temas presentados, para proceder luego a la toma de decisiones y resoluciones, que fueron registradas por el secretario / a de la asamblea.

Un elemento fundamental en la realización de estos eventos fue la decisión de que los talleres se desarrollaran en su mayor parte en kichwa, lo que coadyuvó a un mejor entendimiento y captación de los temas de la capacitación. 
Las deliberaciones culminaron en la escritura del acta de la asamblea, que contiene los pronunciamientos de los participantes y directivos. Las resoluciones fueron tomadas mediante votación simple, ya que los participantes habían dado a conocer previamente sus criterios y razonamientos personales. Las asambleas culminaron con la suscripción del acta por parte de cada uno de los participantes y de los directivos de la comunidad, si bien no todas las asambleas lograron procesar el acta correspondiente (ver más adelante).

Las actas fueron entregadas en forma directa por los dirigentes de las comunidades a los facilitadores o a las oficinas de consulta; pero también fueron remitidas a las federaciones o juntas parroquiales. Todas las actas fueron concentradas luego en el equipo de la UPS, a fin de proceder a su análisis y notarización.

\section{Pronunciamientos}

Analicemos brevemente la dinámica de la participación y de los pronunciamientos de cada comunidad.

En general, fueron convocadas el 97\% (368) de las comunidades indígenas del área, incluyendo comunidades de indígenas y colonos; el 3\% restante no se dejó convocar por problemas organizativos internos o por oposición al proceso de Consulta, normalmente orquestado desde afuera de la propia comunidad. De ellas, se reunieron en asamblea 337 comunidades (el 88.91\%). En distintos sectores (por ejemplo, Tálag y Misahuallí), algunas de las comunidades convocadas se negaron a realizar la asamblea - taller o a pronunciarse, debido a la naturaleza de las actividades que realizaban (ecoturismo), que consideran podrían verse afectadas por la actividad petrolera, y por influencia de un grupo local contrario a la Consulta (ReCoka). Otras comunidades no participaron por falta de interés, por estar en otras ocupaciones, por haber hecho caso omiso de la convocatoria enviada por el presidente de la comunidad o porque el propio presidente de la comunidad se negó a convocar a pesar de la insistencia de sus bases en ser consultadas (una comunidad). A pesar de todo, el porcentaje de realización de asambleas ha sido muy alto (el 89\%).

De las 337 comunidades consultadas, se han pronunciado mediante algún tipo de acta 291 (el 76.78\% del total); de ellas, 263 comunidades han entregado un acta válida, es decir, que contiene el pro- 
nunciamiento de la comunidad y las firmas de los participantes, lo que representa el $90.37 \%$ de las comunidades que han emitido actas, el $78 \%$ de las que han celebrado asamblea y el $69.39 \%$ del total de comunidades existentes en el área de los bloques. El 89.73\% del total de actas válidas se pronuncian por un sí condicionado. Por bloque, sobre el total de actas válidas, se ha pronunciado por un sí condicionado el $90.76 \%$ de las comunidades en el bloque 20, y el $87.34 \%$ en el bloque 29 .

Con relación a las asambleas internas de las organizaciones, que se instalan cuando asisten la mitad de los socios más uno, los dirigentes consideran que la participación ha sido un éxito, sobre todo teniendo en cuenta el contexto adverso que rodeó a la Consulta; de hecho, es difícil lograr más del $60 \%$ de participación en promedio.

En cuanto a la entrega de actas, se ha visto dificultada por varios factores; entre ellos, cabe nombrar los siguientes:

- Poca capacidad de algunas comunidades para redactar las actas. Como la consigna era que el facilitador se retirara para dejar deliberar a la Asamblea, algunas comunidades no pudieron elaborar el acta el mismo día de la asamblea y fueron postergando su entrega.

- Interferencia de otros procesos: ingerencia de organizaciones 'ecologistas' radicales, partidos extremistas, dirigentes antiguos que no entendían el proceso; incidencia de las experiencias de otras comunidades fuera del área (casos Texaco en Sucumbíos y Sarayaku en Pastaza), etc.

- Desinterés y olvido de algunas comunidades, o diferencias fuertes de opinión en la asamblea.

- Chantaje de algunos dirigentes; de hecho, los presidentes algunas comunidades se negaron a firmar un pronunciamiento positivo porque tenían otra posición, y propusieron cambiar el pronunciamiento que había prevalecido en la asamblea.

- Imposición desde los dirigentes de alguna de las organizaciones mayores, que temían perder control o influencia con un pronunciamiento individualizado (y afirmativo) de sus bases; este tipo de actitudes estuvieron influidos visiblemente por grupos externos de 'apoyo'. Esto tendió a suceder, por ejemplo, en ACIA (Pastaza) y en la Cooperativa Rukullakta (Napo), 
Teniendo en cuenta el contexto de la Consulta, y por decisión del equipo del proyecto en consenso con los facilitadores, se resolvió reconvocar hasta en tres ocasiones a aquellas comunidades en las que no se había podido realizar el taller-asamblea, intentando que el derecho al pronunciamiento fuera ejercido en su plenitud. Los informes de cada facilitador dan cuenta de la dinámica de convocatoria, asistencia y pronunciamiento en cada comunidad, así como las razones de las actas faltantes.

Si bien hubiera sido conveniente disponer de un tiempo mayor, la mayoría de las comunidades se sintieron lo suficientemente informadas como para deliberar y adoptar resoluciones. Por otra parte, conviene tener en cuenta que sobre estos procesos pesan enormes pasivos socioambientales, que no pueden ser absueltos en su totalidad de manera inmediata.

De todas formas, considerando las circunstancias desfavorables que acompañaron al proceso (simultaneidad de los episodios de Texaco y Sarayaku; hostigamiento permanente de grupos opuestos a la realización de la Consulta), se ha cumplido ampliamente con los objetivos trazados.

\section{Las Asambleas Intercomunitarias}

\section{Estructura y funciones}

Las asambleas Intercomunitarias son los espacios de expresión y participación del conjunto de los miembros de las comunidades, pertenecientes en términos socio-organizativos a las Federaciones y en términos socio-territoriales a las Juntas Parroquiales. Conforme al Instructivo elaborado conjuntamente entre el equipo UPS y los Presidentes de Federaciones y Juntas Parroquiales (Tena, 27.11.03), el objetivo de estas asambleas era recoger los pronunciamientos de las comunidades para validarlos, complementándolos apropiadamente en función de las orientaciones colectivas. Adicionalmente, otros objetivos eran reflexionar, analizar y discutir en forma conjunta sobre el proceso de consulta previa, sus aciertos y debilidades, así como emitir un pronunciamiento colectivo sobre las posiciones y propuestas, relacionados con la pertinencia de promover o no procesos de explotación hidrocarburífera en sus territorios. En este senti- 
do, la función de la Asamblea Intercomunal fue validar las decisiones de las comunidades; pero no podía ir en contra de ellas si ya había habido un pronunciamiento explícito, salvo cuando el proceso de toma de decisiones hubiera estado gravemente viciado. En este sentido, las decisiones comunitarias podrían, en último extremo, prescindir de la validación de la Asamblea Intercomuna ${ }^{16}$; pero las asambleas intercomunitarias no pueden prescindir de los pronunciamientos comunitarios, una vez emitidos ${ }^{17}$.

Por razones prácticas (facilitar la organización y asistencia de los presidentes de las comunidades), las asambleas se realizaron en las cabeceras parroquiales o cantonales, aunque las convocatorias fueron firmadas por el conjunto de Presidentes de Federaciones existentes en un determinado espacio parroquial, además del presidente de la Junta Parroquial misma. A pesar del estrecho margen de tiempo disponible entre la convocatoria y la realización de las asambleas intercomunitarias, estas se celebraron con absoluta transparencia y de acuerdo a lo establecido en el instructivo elaborado. Las discusiones se desarrollaron de manera profundamente democrática, conforme a mecanismos parlamentarios conocidos y practicados por todos los dirigentes participantes. Los facilitadores se reintegraron en este momento a sus respectivos espacios organizacionales, como un miembro más, aunque calificado por el proceso de formación vivido y la experiencia adquirida. La tarea de conducción de las asambleas fue encomendada a los presidentes y secretarios 'ad hoc' elegidos por los participantes, que asumieron esta labor de manera absolutamente responsable, eficiente y transparente, con el reconocimiento de los participantes.

\begin{abstract}
16 Es el caso de las comunidades cuyos presidentes no pudieron asistir a las asambleas, pero cuya opinión es considerada plenamente legítima para los fines de la Consulta, salvo en caso de que hubiera habido impugnación

17 Existe a veces en las comunidades un mal entendido 'asambleismo', que es utilizado de manera poco democrática por algunos dirigentes para impedir que las comunidades se pronuncien, con el pretexto de que son 'manipulables'. En este sentido, el verdadero camino es seguir exponiendo a las comunidades a procesos de información y capacitación como el realizado a propósito de la Consulta, de manera que estén en condiciones de poder expresar sus propios pensamientos en forma complementaria al de sus dirigentes.
\end{abstract}


La planificación realizada preveía que se llevasen a cabo 15 asambleas intercomunitarias, de las que se celebraron 13 en las siguientes parroquias o sectores:

NAPO: San Jacinto (Archidona), Mondayacu - Cotundo, Pano, Talag, Tena - Chambira (comunidades independientes), Ahuano, Puerto Napo Arosemena Tola, Misahuallí y San Pablo

PASTAZA: Santa Clara, AMA-Arajuno y El Triunfo

ORELLANA: 24 de Mayo

La concurrencia del $68 \%$ de los dirigentes de las comunidades involucradas en la Consulta, considerando la rapidez de la convocatoria, da cuenta de la importancia que las comunidades han otorgado a este proceso, que han avalado y legitimado. En todo caso, se trata de una concurrencia superior al promedio de presencia de las bases a las asambleas convocadas por sus propias dirigencias. La mayoría de las Asambleas fueron realizadas en kichwa.

De acuerdo a la convocatoria, los representantes de las comunidades se reunieron un tiempo aproximado de 8 a 10 horas de trabajo. Los momentos contemplados eran los siguientes: (I) lectura de los pronunciamientos de los presidentes; (II) análisis, discusiones, toma de decisiones y planteamiento de propuestas; (III) elaboración y suscripción del acta.

El primer momento de la asamblea (a.m.) fue la lectura de los pronunciamientos comunitarios transcritos en actas, añadiendo eventuales comentarios respecto a las resoluciones tomadas y las propuestas realizadas.

En el segundo momento de la Asamblea Intercomunitaria (p.m.), se dio paso a la participación de los presentes. Este espacio fue utilizado para recapitular los pronunciamientos de las comunidades y ratificarlos, además de reflexionar, analizar y discutir en forma conjunta sobre el proceso de consulta previa, los pronunciamientos realizados y las propuestas formuladas. La participación fue registrada por el/la secretario/a de la asamblea.

El tercer momento (final de la tarde) fue la elaboración del acta de la asamblea, que contiene los pronunciamientos de los participantes y directivos. Como en el caso de las asambleas comunales, las resoluciones fueron tomadas mediante votación simple, ya que las participantes ya 
habían dado a conocer previamente en forma extensa sus criterios y se remitían a pronunciamientos anteriores realizados por cada comunidad. A continuación se procedió a la suscripción del acta por cada uno de los participantes en la asamblea y de los directivos de la misma.

\section{Pronunciamientos}

En general, como hemos señalado, la participación de los 229 presidentes corresponde al $67.9 \%$ de las 337 comunidades que han realizado asamblea comunitaria, por lo que las Asambleas Intercomunales se instalaron con quórum suficiente.

En la mayoría de los casos los presidentes participantes ratificaron los pronunciamientos realizados por sus comunidades; sin embargo, cabe señalar que algunos presidentes decidieron cambiar el pronunciamiento de sus bases sin el consentimiento expreso de las mismas, existiendo casos, por ejemplo, en los que el anterior sí condicionado se decantó en un pedido de moratoria o en un pronunciamiento en contra. Con estas salvedades, y con relación a las asambleas en las que ha existido algún tipo de pronunciamiento (13/15), los resultados son los que siguen:

- se pronuncian a favor de un sí condicionado al proceso petrolero el $76.4 \%$ de los presidentes;

- se pronuncian contra el proceso petrolero el $13.1 \%$ de los presidentes;

- se pronuncian por una moratoria de la consulta y del proceso petrolero el $7.9 \%$ de los presidentes ${ }^{18}$;

- manifiestan tener opiniones divididas el $2.6 \%$ de los presidentes que participaron en las Asambleas.

El resto de las Asambleas (2/15) no se había pronunciado todavía a la finalización del proceso de consulta (15.12.03), considerando que los plazos fueron alargados dos semanas más para dar ocasión a su pronunciamiento. Después de un proceso tormentoso, la Cooperativa Rukullakta (una única entidad jurídica integrada por 17 sub-centros) se pronunció

18 La moratoria es una tendencia que no apareció en los pronunciamientos comunitarios. Además de un porcentaje minoritario de presidentes individuales de Talag y San Pablo (que votaron en una dirección distinta de la de sus comunidades), la parroquia de El Triunfo (Pastaza) se pronunció colectivamente por la moratoria. La mayoría de las 11 colonias de la parroquia están integradas por colonos serranos, aunque existen también una minoría de indigenas kichwa y shuar. 
colectivamente por el 'no' al petróleo el día 17 de diciembre ${ }^{19}$. Las 20 comunidades de ACIA (Pastaza) no se han pronunciado todavía, por lo que su falta de pronunciamiento ha sido considerada como abstención ${ }^{20}$.

19 La Cooperativa Rukullacta (Napo), adscrita a la FONAKIN, ha sido la organización que ha recibido mayor apoyo durante el proceso de Consulta para la realización de innumerables asambleas internas, muy por encima del promedio de apoyo brindado, debido a su compleja estructuración interna. Con todo, han existido intentos evidentes de condicionar los resultados de estas asambleas por parte de miembros de Recoka, junto con integrantes de otros grupos 'ecologistas'y algunos dirigentes locales afines a sus planteamientos. En una ocasión llevaron buses llenos de gente para que corearan incesantemente las consignas de sus líderes e intentaran convertir la asamblea de la Cooperativa en 'asamblea del pueblo'. Los miembros de la Cooperativa, sin embargo, desestimaron esta sugerencia y les invitaron a retirarse, declarando que sus resoluciones debian ser tomadas solamente por ellos, sin la presencia de 'mishus' (mestizos). Por otra parte, ha existido una flagrante falsificación de una convocatoria interna del Presidente de la Cooperativa, ya que se emitió por la radio una convocatoria supuestamente firmada conjuntamente por la Cooperativa, miembros de Recoka y otras organizaciones ecologistas, en la que se convocaba a la FONAKIN (Napo), la CONAIE, la CONFENIAE, el CODENPE y otras instituciones nacionales a participar en la asamblea de la Cooperativa. Salvo asesores directos de algunos de los grupos mencionados, venidos desde Quito, nadie más participó en esta Asamblea; el Presidente de la CONFENIAE participó en una asamblea posterior. El entonces Presidente de la Cooperativa tuvo que hacer una declaración pública por Radio Ideal del Napo, desmintiendo la convocatoria.

20 En el caso de la Asociación de Comunidades Indígenas de Arajuno - ACIA (Pastaza), institución miembro de la OPIP, la situación ha sido también compleja. ACIA recibió un apoyo especial en el proceso de Consulta, al hacer posible la selección de dos facilitadores en lugar de uno (número proporcional a la cantidad de comunidades), en consideración a la dispersión territorial del área. En el Taller Intercomunal de capacitación, impartido a alrededor de 50 presidentes y miembros de las comunidades y de la directiva de ACIA, todos los participantes manifestaron su agradecimiento y felicitaron efusivamente al equipo de la UPS, empezando por el presidente de ACIA. Como puede apreciarse por los resultados de la evaluación, fue uno de los talleres mejor evaluados del proceso. En este taller fue validado por primera vez en forma conjunta el instructivo para las asambleas comunitarias, en el que se recoge la posibilidad de realizar un pronunciamiento a favor o en contra del petróleo.

Posteriormente se realizaron las asambleas-talleres en todas las comunidades. Algunas comunidades se pronunciaron favorablemente al inicio del proceso petrolero y transcribieron su pronunciamiento en actas (de hecho, algunas de estas actas fueron entregadas al equipo de la UPS), aunque poniendo condiciones drásticas que hubieran transformado el si en un 'no' en caso de incumplimiento de las propuestas. Aparentemente, este hecho intranquilizó a algunos dirigentes de Pastaza (que habian adoptado ya al nivel provincial una posición a favor de la moratoria de la explotación petrolera, a partir de experiencias previas negativas, como la de Sarayaku) y a miembros de organizaciones de apoyo no-indígenas. En la última asamblea deliberativa, convocada por la directiva de ACIA (diciembre del 2003) y en la que participaban representantes de la mayoría de las comunidades, la palabra fue monopolizada rápidamente por miembros de 3 comunidades, apoyados por un grupo de 'solidaridad' compuesto por estudiantes de la Universidad Central, que invitaron a la asamblea a pronunciarse contra el petróleo. Con todo, el pronunciamiento colectivo quedó diferido para una asamblea posterior, hasta ahora pendiente. 
Más allá de los pronunciamientos de los presidentes (la mayoría a favor de un sí condicionado a favor del petróleo), el resultado principal de estas Asambleas Intercomunales ha sido la validación global del proceso de Consulta (no se registraron denuncias sobre irregularidades en los procedimientos y en la participación), y las tendencias generales de los pronunciamientos comunitarios.

\section{Resoluciones}

En los pronunciamientos de las 14 Asambleas Intercomunitarias que se reunieron prevalecen las resoluciones relacionadas con ocupación de la fuerza de trabajo local, capacitación-educación, fortalecimiento organizativo, fondo de compensaciones, protección de áreas sensibles, proyectos productivos, infraestructura social y productiva y salud.

En realidad, desde un repensamiento global de las propuestas realizadas en el marco del Comité de Presidentes de Federaciones y Parroquias, aparece claro que la creación de un Fondo de Compensaciones permitiría absolver la mayoría de las demandas, bajo la forma de una capitalización de los aportes de las empresas, más otras donaciones internacionales, que serían redistribuidas hacia las comunidades bajo la modalidad de cuotas por población y petróleo. Los fondos serían manejados bajo la modalidad de un fideicomiso (ver "Propuestas de las comunidades").

\section{Notarización de las Actas comunales e intercomunales, y validación por parte de los Presidentes de Federaciones y Parroquias}

Una vez consignadas las Actas, tanto comunitarias como intercomunales, estas fueron fotocopiadas y llevadas a la notaría del Cantón Tena para su debida notarización como copias fieles del original. Fueron notarizadas como copia fiel del original un total de 263 actas comunitarias y 14 actas intercomunales.

La validación de las Actas comunales e intercomunales ha contado con una última instancia que le ha dado una legitimación adicional, ya que han sido revisadas por los Presidentes de Federaciones y Juntas Parroquiales, comparando el original y las copias notariadas, y avaladas como fidedignas. Al mismo tiempo, este hecho ha permitido una apropiación del proceso por parte de los representantes de las organizaciones. 
Conforme a las modalidades previstas, los pronunciamientos, opiniones y propuestas de las asambleas fueron presentados formalmente en cada una de las Oficinas de consulta (Archidona y Ahuano), donde han sido revisados y completados, para dar inicio al proceso de sistematización por parte de la Universidad Politécnica Salesiana, en cuanto encargada de facilitar el proceso de Consulta.

\section{Las propuestas de las comunidades ${ }^{21}$}

\section{Antecedentes}

En el marco de la reciente Consulta Previa a los Pueblos Indígenas de los bloques 20 y 29 de la Amazonia Ecuatoriana, propiciada por el Estado en apoyo al ejercicio de un derecho colectivo, amparado por el Convenio 69 de la OIT y reconocido por la Constitución, la mayoría de las organizaciones y comunidades del área han emitido pronunciamientos globales favorables al inicio de un proceso de exploración y explotación petrolera.

Las decisiones de las comunidades están sustentadas en los siguientes factores:

(I) el reconocimiento del derecho del Estado a utilizar el petróleo, que constituye una parte fundamental de los ingresos fiscales;

(II) la convicción de que es posible controlar en gran medida los riesgos ambientales y sociales que acompañan al proceso petrolero (tecnologías limpias, respeto a las áreas sensibles, vigilancia social);

(III) la perspectiva de poner en marcha procesos tendientes a una mejor distribución de los ingresos derivados del petróleo para promover el desarrollo regional, tanto bajo la modalidad de un Fondo Regional de Compensaciones al inicio del proceso petrolero (5\% de las inversiones de las compañías petroleras, por fases; donaciones internacionales), como de una redistribución más equitativa de la renta petrolera (Estado).

21 Se trata de un resumen de propuestas más específicas, ya presentadas al Estado y básicamente aceptadas. Estas propuestas están en proceso de ser ampliadas y concretadas durante la etapa postconsulta. 
En este sentido, se trata de un SÍ CONDICIONADO, ya que forma parte indisoluble de dicho pronunciamiento la formulación de una serie de propuestas socio-ambientales, que tienen como referente el Convenio 169 de la OIT (suscrito por el Ecuador), la Constitución Política del Estado y las demás normativas ambientales de la República (Ley de Gestión Ambiental, Reglamento Sustitutivo de Operaciones Hidrocarburíferas, normativas de Petroecuador).

Las propuestas concretan los planteamientos de los pueblos indígenas y han sido elaboradas durante un período de un año y medio, entre agosto del 2002 (inicio del Diagnóstico y los primeros Talleres de Metodología de Consulta), y la finalización de la Consulta Previa en diciembre del 2003. En el marco de la Consulta, las propuestas fueron debatidas en alrededor de 400 talleres y asambleas (comunales, intercomunales y de presidentes de Federaciones y Parroquias) durante los meses de octubre, noviembre y diciembre del presente año.

De las malas prácticas de muchas de las empresas petroleras en el pasado reciente (daños al medio ambiente, a la cultura y a las organizaciones locales), es preciso extraer difíciles 'lecciones aprendidas' para que se conviertan en referente del futuro proceso de exploración y explotación en el área de los bloques. En esta dirección, las propuestas plantean la necesidad de realizar un esfuerzo mucho más consistente por:

- redefinir la 'cultura petrolera' de muchas compañías (evitando aproximaciones directas a cada espacio comunitario, que se presta a manipulaciones y a la división de las organizaciones);

- implementar tecnologías limpias;

- asegurar la participación de las poblaciones locales en el marco de sus propias instituciones representativas;

- apoyar iniciativas de compensaciones colectivas y mejor redistribución del ingreso, para que los habitantes de la región puedan vivir en dignidad.

Por otra parte, como ha sido evocado al inicio, el fundamento del Convenio 169 de la OIT, suscrito por el Ecuador, es el reconocimiento de las aspiraciones de los pueblos indígenas "a asumir el control de sus propias instituciones y formas de vida y de su desarrollo económico, y a mantener y fortalecer sus identidades, lenguas y religiones dentro del marco de los estados en los que viven". En forma paralela a las modalidades del proceso de Consulta Previa (prescritas por el Reglamento), el 
proceso de ejecución de alternativas de desarrollo de los bloques deberá contar también con la participación directa de las mismas organizaciones representativas de las comunidades (Federaciones y Parroquias); para ello, deberán seguir siendo capacitadas, a fin de que estén en grado de desempeñar un rol protagónico en el proceso de toma de decisiones y en el control social del proceso de exploración y explotación petrolera.

En este sentido, con la realización de la Consulta Previa existen las condiciones para dar una vuelta de página a las tradicionales prácticas petroleras (algunas de ellas en proceso de cambio parcial en algunos bloques) e inaugurar una nueva etapa que podría tener importantes consecuencias para la región y para el país.

\section{Capacitación}

El proceso de Consulta ha contribuido poderosamente a elevar los conocimientos, la conciencia y el nivel de organización local. Sin embargo, frente a los inmensos pasivos sociales no cubiertos todavía por las instituciones del Estado ni por la cooperación internacional, quedan al descubierto una serie de aspectos que las organizaciones solicitan satisfacer. La primera serie de propuestas se relaciona con la profundización de las distintas temáticas relacionadas con derechos colectivos, participación y vigilancia social, normativas petroleras, tecnologías limpias, monitoreo socio-ambiental, fortalecimiento organizativo, gestión del desarrollo local y manejo de conflictos.

Estas demandas a corto plazo están en proceso de ser satisfechas por el Estado, a través de la ampliación y focalización de la capacitación durante el período postconsulta previo a la licitación petrolera. Otras demandas de capacitación y profesionalización se relacionan con la implementación de un Fondo de Compensaciones (ver más adelante).

\section{Aspectos ambientales y sociales de los contratos}

Las propuestas de las comunidades se relacionan también con el cumplimiento de las normativas ambientales, en particular la implantación de un Sistema de Gestión Ambiental que prevenga, disminuya y/o 
controle los impactos ambientales, dando cumplimiento a la legislación ambiental, desarrollando medidas preventivas y/o correctivas, y adoptando normas de calidad ambiental tipo ISO 14.001.

Junto a ello, piden que se concrete la realización de Estudios de Impacto Ambiental Participativos (EIA-P) y la implementación de procedimientos de vigilancia social, inscritos en el marco institucional y participativo del Fondo de Compensaciones (ver más adelante) y financiados a través de él. Plantean que el conjunto de acciones de control, vigilancia y evaluación de las actividades hidrocarburíferas se realice de manera organizada e independiente, planteando temas relevantes para la vida comunitaria, y contando con medios para difundir sus acciones y resultados a la sociedad.

Conforme a las normativas de Petroecuador, también planean que los seguros de las compañías petroleras cubran los riesgos de vida y salud humanas, la contaminación, y eventuales afectaciones al ecosistema, a la flora y a la fauna, en el entendido que la afectación del ambiente será de entera responsabilidad de las compañías.

Por otra parte, solicitan que en cada una de las etapas del proceso petrolero sean implementadas las tecnologías más limpias disponibles, descritas y analizadas durante la Consulta ${ }^{22}$.

\section{Indemnizaciones y compensaciones}

Las propuestas incluyen la indemnización directa de los daños eventuales causados a las fincas, proyectos productivos o propiedades. Para ello, se recurrirá a métodos como costo-beneficio y costos de oportunidad, sobre la base de precios actualizados de mercado, considerando la extensión e intensidad del daño (total o parcial) y el tiempo que va a durar

\footnotetext{
22 Ver Oportunidades y riesgos del petróleo (Folleto de capacitación $n^{\circ} 3$. Quito, UPS, 2003). Además de las tecnologías conocidas y experimentadas en los bloques más 'sostenibles', es importante implementar tecnologias térmicas avanzadas para la extracción de los petróleos más pesados del tipo 'pungara', abundantes al norte del área de los bloques, obteniendo y usando sosteniblemente el agua requerida en cantidad y calidad. De todas maneras, aunque quedan muchos asuntos por resolver, los avances técnicos de las operaciones a partir de los noventa permiten demostrar que es posible lograr una importante disminución de riesgos y de impactos ambientales directos (Albán 2003: 147)
} 
(temporal o permanente). Adicionalmente, se recurrirá a métodos de valoración de todos los bienes forestales (maderables y no maderables) y de los servicios ambientales que sean afectados (agua, aire, control de la erosión, etc.), sugeridos por el Diagnóstico Socio-económico de los bloques. No obstante, en la perspectiva actual de las comunidades, el objetivo es que las medidas socio-ambientales a ser implementadas prevengan los impactos y eviten o minimicen la necesidad de realizar indemnizaciones.

En cuanto a las compensaciones, las comunidades plantean que la compañía o compañías titulares inviertan un porcentaje del total de sus inversiones por fase en la creación de un Fondo de compensaciones colectivas, cuyas ventajas con las siguientes:

Permite el planteamiento de propuestas que superen el inmediatismo y el coyunturalismo, en el marco de un plan global de desarrollo de los bloques que oriente las acciones del Fondo.

Salvo en el caso de indemnizaciones directas o compra directa de bienes y servicios a un privado, este Fondo sustituye la necesidad de que la petrolera realice inversiones directas en las distintas subáreas de los bloques, que serán canalizadas a través del Fondo.

En este sentido, crea las condiciones para evitar el riesgo de manipulación y conflicto, al soslayar la relación directa de los antiguos 'relacionadores comunitarios' con cada comunidad y familia ${ }^{23}$.

El Fondo se estructurará a partir del 5\% de las inversiones petroleras por fase, complementado por otras posibles inversiones y donaciones de organismos internacionales, que serán colocadas en un fideicomiso. La compañía petrolera se relacionará directamente con los representantes del Fondo (de mayoría indígena) y sus distintas instancias (Directorio, Comité Técnico, Comité Administrativo, Comités subregionales), conforme al organigrama de funciones en proceso de definición.

23 En las propuestas se distingue cuidadosamente entre "indemnizaciones" (pago por los daños causados a un determinado propietario o comunidad) y "compensaciones colectivas", cuya justificación se basa en las consecuencias de la irrupción de las compañias en el espacio comunitario, e incluye tanto el uso directo o indirecto de este espacio, cuanto los impactos asociados (ambientales y sociales) cuya medición es difícilmente cuantificable (ver Indemnizaciones y compensaciones para el desarrollo regional. Folleto de capacitación $n^{\circ} 4$. Quito, UPS, 2003). Esta diferenciación ayuda a evitar eventuales expectativas de derrames susceptibles de ser indemnizados (ct. Bustamante 2003:42-43), ya que los verdaderos beneficios se focalizan en las compensaciones colectivas para el desarrollo regional (ver más adelante). 
En este contexto, todas las comunidades se benefician proporcionalmente, según cuotas diferenciales de población y producción petrolera por área, contribuyendo a controlar las inequidades en el proceso de desarrollo regional ${ }^{24}$.

El conjunto de recursos canalizados por el Fondo se invierte en el marco de un plan global de desarrollo de los bloques, con líneas de proyecto viables que se complementan con otras propuestas en curso dentro del área ${ }^{25}$. Las comunidades preparan propuestas según la cuota que les corresponde (población y petróleo), con apoyo de los especialistas del Fondo. Estas propuestas son revisadas, realimentadas y aprobadas por las distintas instancias de Fondo, y ejecutadas por las comunidades con el correspondiente asesoramiento técnico ${ }^{26}$.El Fondo poseerá tanto componentes reembolsables (proyectos productivos) como no reembolsables (investigación e información, capacitación y profesiona-

\begin{abstract}
24 Este tipo de propuesta va más allá de las modalidades habituales de distribución clientelar o de los típicos fondos concursables, donde la oferta es capturada por quienes tienen mayor capacidad de demanda. En este caso, no se trata de ningún 'fondo concursable', sino de un fondo por cuotas, de manera que todos reciben algún tipo de beneficio. Una vez cumplidos los requisitos para la asignación de recursos (ver nota 21), estas cuotas se asignarían en función de dos criterios básicos: (I) número de habitantes indígenas rurales por Parroquia (incluyendo también las comunidades conformadas por colonos), que se beneficiarían proporcionalmente con el $50 \%$ de los recursos disponibles, y (II) cantidad de petróleo existente en una determinada zona (el otro 50\%), considerando la mayor exposición a riesgos por parte de las comunidades y familias en cuyos predios se localizarán las actividades hidrocarburiferas. De esta manera, se pondrán las bases para conjugar la equidad con la distribución proporcional de los beneficios.

25 Es tan emblemática como patética la falta de apropiada sinergia y coordinación entre instituciones de desarrollo, organizaciones indígenas y entidades gubernamentales, algo que afecta tanto al petróleo (ver Barrera de Jorgenson 203: 182-83), como a las demás dimensiones del desarrollo (ver Izko 2003a. 80; Ib. 2003b: 115 ss., con relación a las políticas forestales sudamericanas).

26 En este sentido, aunque todas las comunidades tienen asegurado el apoyo que les corresponde, el momento y las modalidades de asignación de la cuota dependen de la calidad de las propuestas y de la real capacidad adquirida para su ejecución por parte de los actores locales, cuya promoción es sobre todo responsabilidad de los funcionarios del Fondo de Compensaciones, en diálogo permanente con las comunidades.
\end{abstract}


lización, fortalecimiento institucional y organizativo, infraestructura social, rescate y dinamización cultural).

Finalmente, las comunidades solicitan que este conjunto de propuestas figuren en las bases de las licitaciones, solicitud que está en proceso de ser considerada favorablemente por el Estado.

\section{Análisis del proceso y de sus resultados}

1. El petróleo es un tema particularmente complejo, que ha dado lugar a polarizaciones radicales, desde el más trágico pesimismo socioambiental hasta una variada gama de optimismos tecnológicos ${ }^{27}$. Estas contraposiciones se sitúan en la raíz de esos 'diálogos fragmentados' que caracterizan el escenario socio-ambiental ecuatoriano y, más específicamente, el de la RAE; de hecho, el petróleo suele ser visto, alternativamente, como el causante de todos los males o como la única oportunidad para el desarrollo del Ecuador, y tiene como correlato el intento de imponer el proyecto petrolero a cualquier costo o impedirlo a través de la creación de un escenario de confrontación e incertidumbre.

En este marco, la Consulta representa una gran oportunidad de ordenamiento del caos socio-ambiental y económico que asedia al sector petrolero ${ }^{28}$, ya que constituye la institucionalización de una práctica democrática, generadora de acuerdos entre la sociedad y el Estado sobre el alcance y las características de la operación petrolera.

2. Por otra parte, conviene señalar que, antes que un pronunciamiento con relación al proceso petrolero, se trataba del ejercicio de un

\footnotetext{
27 Un ejemplo del primero es el libro de Kimerling (1993), mientras que la apología de las 'tecnologías de punta' (en proceso de aplicación por parte de compañías como AGIP, Occidental o REPSOL-YPF) constituirian ejemplos elocuentes de optimismo tecnológico (cf. Bustamante 2003: 28). Sin embargo, es importante contextualizar estas posiciones en las distintas situaciones socioambientales donde cobran arraigo. En el caso de los bloques 20 y 29, las propuestas indigenas intentan recoger las mejores prácticas existentes, adecuándolas a su propio contexto. Ver, entre otros, Fontaine 2003, Acosta 2003, AAVV 2003 a y b para una apreciación global de los antecedentes y tendencias relativos a la geopolítica, la cultura y la economía política del petróleo.

28 Albán 2003:142
} 
derecho colectivo, además de un derecho ciudadano, avalado por la Constitución de la República en ratificación de Convenios Internacionales, que acreditan a los pueblos indígenas en cuanto tales como sujetos de este derecho. En este caso, a los derechos derivados de la participación ciudadana se unen los derechos derivados de la convocación colectiva, aplicada a decisiones vitales sobre el control y manejo de recursos naturales, con implicaciones para el país y para las poblaciones locales.

Este hecho tiene implicaciones importantes para el desarrollo de la región. En cuanto ciudadanos, los indígenas constituyen una minoría relativa con respecto a los habitantes de las ciudades amazónicas y los grupos mestizos rurales, por lo que pareciera corresponderles una 'cuota de progreso' proporcionalmente menor con relación al resto de la población. En cambio, como pueblos indígenas requieren un tratamiento diferencial y preferencial, tanto con relación al proceso de explotación, como con relación a la distribución de la renta petrolera: ellos son los habitantes originarios de los territorios amazónicos, han soportado sucesivas oleadas 'civilizatorias' por parte de la sociedad mayor y podrían ser los más afectados por el petróleo, porque son los que habitan en mayor número las zonas extractivas y son también los más vulnerables.

Adicionalmente, conforme al Convenio 169 de la OIT, el proceso de ejecución de alternativas de desarrollo de los bloques deberá contar con la participación protagónica de las mismas organizaciones representativas de las comunidades, en cuanto a la toma de decisiones y el control social del proceso petrolero.

3. La experiencia de los bloques 20 y 29 está permitiendo transparentar todo un juego de oposiciones, que se inscriben en el marco de la relaciones de poder y conflicto, entendido como un "intercambio mutuo e intencional de sanciones negativas o comportamientos punitivos", que disminuye las probabilidades del otro de alcanzar los objetivos que persigue $^{29}$. Cuanto más importantes y mutuamente excluyentes son los intereses en juego, y cuanto más disminuyen las posibilidades de alcanzarlos, tanto más violencia potencial es generada en el conflicto.

\footnotetext{
29 El poder debe ser entendido, precisamente, como la voluntad de estructurar el posible campo de acción de los otros, a través del control de sus acciones, haciendo más viables determinados tipos de comportamiento e inhabilitando o anulando otros (Foucault 1988: 14-15; Wolf 1990: 587; cf. Izko 1995).
} 
Paradójicamente, en este primer momento los 'opositores' de las comunidades no son tanto el Estado o las petroleras, porque el primero ha posibilitado el ejercicio de sus derechos y las segundas (a instancias del Estado y de las comunidades) están dispuestas al diálogo, a utilizar tecnologías limpias, y a apoyar el involucramiento comunitario y la constitución de un fondo de compensaciones. En la percepción de las comunidades, los principales oponentes son, más bien, grupos de reales o supuestos 'ecologistas' radicales que han querido impedir el ejercicio de sus derechos o que pretenden impugnar la legitimidad de sus conquistas. Puede esperarse que cuando inicie el proceso petrolero surjan nuevas coyunturas que posicionen a las compañías petroleras o al mismo Estado como posibles antagonistas, aunque no se trata de algo deseable; en todo caso, es necesario prevenir los posibles impactos de la exploración y explotación, solventando dudas y anticipando problemas que puedan surgir en el ejercicio real de la vigilancia comunitaria, en el manejo del fondo de compensaciones, en la identificación de la cuantía de las indemnizaciones por eventuales daños causados, etc. Pero, en este momento, el campo de oposiciones está ambiguamente signado por la confrontación entre comunidades y grupos de 'ecologistas' fundamentalistas, y -potencialmente- entre comunidades a favor y en contra del petróleo (estas últimas la minoría).

Por otra parte, a la luz de los resultados del proceso de Consulta, es importante señalar que, si bien el Estado, las petroleras y las comunidades tienen intereses claramente distintos, no se trata de intereses completamente antagónicos; de hecho, los acuerdos que hagan viable el proceso petrolero pueden surgir solamente de una convergencia al menos parcial entre los tres tipos de actores. Y este hecho constituye un importante referente para la superación de eventuales conflictos.

Al contrario, pareciera negada de antemano la posibilidad de acuerdo entre las comunidades que se han pronunciado por el 'sí' y los grupos 'ecologistas' (una minoría combativa), ya que estos grupos buscan deslegitimar por cualquier medio los pronunciamientos comunitarios y la Consulta misma; en otras palabras, niegan las bases mismas sobre las que podría construirse una convergencia posible.

Frente a los graves problemas inherentes al sector petrolero o provocados por él (daños socio-ambientales, inversión ineficiente e inequitativa de los ingresos del petróleo, etc.), algunos indígenas, en alianza con ONGs, han intentado desplegar frente a las compañías y 
frente al Estado toda una gama de respuestas posibles. Estos antecedentes han justificado una actitud de rechazo en distintas zonas de la Amazonia y hubieran justificado una actitud de extrema cautela en el caso del Napo. Pero cuando ha quedado ya patente, tras una Consulta transparente y legítima, el intento de las comunidades de revertir esta situación, ¿cuál es exactamente el sentido de seguir oponiéndose? Probablemente, la respuesta se mueve en la dirección de posiciones fundamentalistas irreductibles, acompañadas por la incredulidad y el insoportable escándalo de que una vasta área como el Napo, Orellana y parte de Pastaza se haya pronunciado a favor de un sí condicionado al petróleo; incredulidad que se nutre de uno de los mitos más cultivados por determinados grupos de ecologistas durante los últimos años: la identificación del indígena con el rechazo al petróleo (ver más adelante).

En todo caso, un análisis sumario de las interacciones actuales sugiere que estas son las principales tendencias de los opositores:

- deslegitimar el proceso, sus resultados y sus principales actores;

- intentar sembrar confusión entre las comunidades que se han pronunciado por el 'sí' y buscar más adeptos a favor del 'no';

- profundizar la oposición entre las comunidades para seguir justificando su propia actuación.

Considerando la irreversibilidad de la Consulta, de sus resultados y de sus implicaciones, la única alternativa realmente plausible para solucionar el inevitable conflicto, sería aceptar las razones de la mayoría y convertirse en acompañantes críticos del proceso.

4. Ha pesado fuertemente sobre el proceso de Consulta la simultaneidad del juicio a la Texaco en Lago Agrio (Sucumbíos) y la dramática situación de Sarayaku en Pastaza, que han sido manejadas por los opositores a la Consulta Previa como los paradigmas de cualquier proceso petrolero en el futuro de la Amazonia, inhibiendo o poniendo obstáculos a la participación.

Los indígenas del área de los bloques opinan que ambas situaciones (Texaco y Sarayaku) deben ser solucionadas, compensando a los perjudicados y abordando el conflicto desde sus raíces. Pero también son conscientes de que el pasado no tiene por qué volver a repetirse. Desde su punto de vista, la realización de la Consulta Previa ha tenido precisamente el sentido de evitar en adelante este tipo de situaciones, contribu- 
yendo a controlar los daños y procurando un beneficio mucho más consistente para las comunidades.

En este sentido, el 'sí condicionado' es al mismo tiempo, en muchos sentidos, un NO a la manera cómo el petróleo ha sido extraído y utilizado, a los procedimientos de las petroleras y del mismo Estado:

- el pronunciamiento comunitario representa la exigencia de que el Estado ('su' Estado) haga cumplir las normativas ambientales;

- los pueblos indígenas exigen que las nuevas condiciones se cumplan (tecnologías limpias, vigilancia social, fondo de compensaciones);

- las compañías petroleras deberían entender claramente que las estrategias basadas en la 'cultura petrolera' de los relacionadores comunitarios, con sus intentos de chantaje y de corrupción, son cosas del pasado;

- en este sentido, como sucede con los recursos renovables (que se convierten en no renovables cuando su uso es insostenible), también el 'sí' puede ser revertido si no se cumplen las condiciones pactadas con las comunidades.

5. Con relación al pasado del área de los bloques, el común rechazo del proyecto petrolero por parte de comunidades y grupos ambientalistas se fundamentaba en razones distintas, que sustentaban una aparente convergencia. Mientras algunas ONGs y grupos ecologistas niegan el petróleo en cuanto tal, amparados en convicciones morales o en posiciones fundamentalistas, muchos indígenas niegan sobre todo las condiciones en las que se ha producido hasta ahora la explotación petrolera; pero estarían abiertos a reconsiderar su posición en caso de que existieran evidencias de que el Estado y las petroleras estén realmente dispuestas a poner todos los medios para prevenir los daños socio-ambientales, facilitar el control comunitario y distribuir los beneficios del petróleo.

En este sentido, más allá de la capacidad de manipulación de los distintos gobiernos, el movimiento indígena no es un actor monolítico. Sin duda, seguirá teniendo posiciones comunes frente al Estado y la sociedad civil no indígena, en reivindicación de los propios derechos; pero manteniendo, al mismo tiempo, posiciones pluralistas en su interior. A partir de ahora, no puede decirse que el rechazo al petróleo en cuanto tal sea un atributo del movimiento indígena, aunque sí el rechazo a todo lo que podría obstaculizar un proceso realmente participativo, 
redistributivo y con control de los impactos ambientales. Esta es una de las implicaciones del pluralismo de los pueblos indígenas, que tiene como correlato la consolidación de una capacidad de procesamiento de las diferencias internas.

6. Tal vez la principal lección que deberíamos extraer los socioambientalistas es dejar de juzgar a los indígenas desde parámetros objetivistas (biologistas, ecologistas o basados en ciertos postulados de política económica), que dictaminan de antemano qué es lo mejor o lo peor para ellos. En esta longitud de onda, cuando sus comportamientos no siguen las reglas de juego trazadas, pensamos que ha tenido que haber algún error. En la opinión de no pocos ambientalistas (o, al menos, a juzgar por sus actitudes prácticas), la gente es todavía un molesto rodeo en el camino hacia la conservación de la naturaleza ${ }^{30}$.

Desde experiencias como Texaco y Sarayaku, existían expectativas de que los pronunciamientos de los bloques 2 y 29 serían contra el petróleo. No ha sido así. En lugar de sacar lecciones pertinentes, algunos grupos intentan todavía demostrar que la Consulta no ha sido legítima. Y este es precisamente el escándalo: los indígenas tendrían que haberse pronunciado contra el petróleo. ¿Por qué? Siguen acumulando evidencias 'objetivas': el petróleo es malo para el planeta, los daños ambientales y sociales son inevitables, la riqueza ha sido mal distribuida... Niegan cualquier desarrollo posible en nombre del pasado, en lugar de preguntarse cómo puede ser revertido, al menos en parte.

\footnotetext{
30 Estas actitudes no están muy lejos de las 'imágenes distorsionadas' y del 'ecomesianismo' a que alude Gudinas, que es necesario balancear con la conciencia de la incertidumbre y del riesgo (2003:161-163). En otro lugar (Izko 2003b: 64 y ss.), hemos definido el desarrollo sostenible a partir de la "ógica de la apropiada imperfección', en contraposición a la lógica de la eficacia inmediata que rige los objetivos de muchos especialistas. En esta dirección, son fundamentales los 'principios progresivos' del desarrollo sostenible (minimizar el daño, optimizar los usos), en la perspectiva de manejar los recursos desde las presiones y las lógicas productivas de la gente.
} 
¿Qué piensan los indígenas? ¿Cuáles son sus percepciones y sus lógicas culturales? ¿Cuáles son sus plazos? ¿Están todavía en esa 'salvaje inocencia', autosuficiente y autocontenida, que les es atribuida por algunos operadores sociales para satisfacer sus propias veleidades intelectuales o compensar los males de su civilización? Los indígenas siguen siendo en muchos sentidos una construcción de nuestros sucesivos imaginarios, hechos a la medida de nuestros preconceptos y de nuestras ideologías, herederas a menudo de una visión sustantiva y estática de la cultura y de la identidad $^{32}$. Y si no coinciden con ellas, pensamos que han sido engañados; una vez más, de otras maneras, los indígenas no pueden ser sino manipulados ${ }^{33}$.

Los indígenas son conscientes de que la búsqueda de alternativas energéticas es una prioridad mundial. Pero piensan también que, ante la falta de alternativas inmediatas, el Ecuador sigue necesitando el petróleo y es muy probable que lo siga explotándolo durante algunas décadas más; por otra parte, la supresión radical del petróleo, sin otras alternativas disponibles, crearía un mayor caos socio-ambiental, considerando la actual dependencia de este recurso. En este sentido, el desarrollo petrolero es uno de los medios con los que cuenta una sociedad, si así lo decide y dispone, para la búsqueda de su sostenibilidad económica, ambiental y social ${ }^{34}$. Sin embargo, la misma naturaleza del petróleo como recurso no renovable y contaminante, exige identificar urgentemente otras alternativas energéticas e invertir en forma mucho más focalizada los ingresos petroleros en la diversifica-

\begin{abstract}
31 Fontaine (2003:102) postula el recurso al concepto de 'ógicas racionales' de los actores, en contraposición a necesidades intereses, motivaciones o relaciones de fuerza. Aunque esta aproximación es oportuna y necesaria, las lógicas racionales' de los actores (entendidas como posiciones argumentadas, elevadas al plano del discurso 'explicado') están inevitablemente signadas por adscripciones culturales en las que - como sucede en el caso de las culturas nativas - son muy importantes los aspectos no verbales y simbólicos (gestos, silencios, posiciones 'de facto'...), por lo que también puede decirse que determinados comportamientos transparentan lógicas que no siempre pueden ser elevadas al nivel discursivo y que es necesario descifrar. De ahi la necesidad de activar mediaciones hermenéuticas que permitan 'traducir' el conjunto de códigos culturales nativos, para aproximarlos a una lógica discursiva 'de racionalidad ampliada'.
\end{abstract}

32 Cerbino (2003) analiza algunos de los 'males' que aquejan a la cultura ecuatoriana contemporánea, muchos de ellos aplicables a la situación que consideramos.

33 Muratorio 1994.

34 Potes 2003: 157. 
ción 'sostenible' de la economía nacional y en la disminución de la misma dependencia del petróleo.

Por otra parte, desde las percepciones indígenas del área los bloques, una de las razones del 'sí' condicionado al petróleo es el fracaso o la insuficiencia de los modelos de desarrollo. Les hemos ilusionado con un 'progreso' que no acaba de llegar, en ninguna de sus formas. Existen iniciativas laudables, pero -desde su percepción- insuficientes, lentas, discontinuas, focalizadas, difícilmente replicables. Sienten (y así lo han analizado en los talleres) que actividades alternativas como el turismo comunitario o el aprovechamiento de la biodiversidad benefician solo a unos pocos y de manera limitada ${ }^{35}$; pero piensan, al mismo tiempo, que una apropiada inversión de los excedentes del petróleo podría consolidar propuestas para el desarrollo sostenible de sus comunidades, en la perspectiva de constituirse en una 'oportunidad para la conservación',

En este sentido, la percepción del desarrollo que tienen los pueblos indígenas del área de los bloques no es clausurar sus territorios para habilitar un proceso exclusivamente endógeno que nunca acaba de llegar, sino abrirlos a una explotación petrolera controlada, cuyos réditos hagan posible el desarrollo local ${ }^{37}$. Sus respuestas son, seguramente, un

35 Dos de las comunidades líderes en el campo del ecoturismo regional se han pronunciado por un si condicionado. No solamente han dicho si los indigenas pobres y menos capacitados... En la asamblea parroquial de Pano, uno de cuyos recursos 'oficiales' es el ecoturismo, se promovió una discusión cuyo desenlace fue que el ecoturismo solo beneficiaba a 12 familias y-parcialmente- a 1 comunidad (alrededor del $5 \%$ de la población). En este sentido, es importante apreciar, no solo la existencia, sino la intensidad y la cobertura real de las prácticas alternativas de desarrollo, asi como su capacidad de sustituir las prácticas que conducen a la degradación de los ecosistemas, en sinergia con las actividades económicas más sostenibles (ct. Izko 2003: 66).

\section{Barrera de Jorgenson 2003}

37 En este sentido, asistimos a una curiosa paradoja: por un lado, Ecuador está dejando de ser una prioridad para un buen sector de la cooperación internacional (si no en cuanto a su presencia, si al menos en cuanto a su intensidad), que niega más apoyo al país con el argumento de que posee importantes recursos naturales (petróleo, camarones, flores, banano...); por otro lado, determinados sectores, apoyados también desde otros frentes de la cooperación internacional privada, hacen indecibles esfuerzos por impedir que el Ecuador produzca petróleo, que es uno de los principales recursos susceptibles de ser invertidos y distribuidos equitativamente en el desarrollo nacional. 
reto para ellos mismos; pero son 'sus' respuestas y solo a partir de ellas se podrá seguir explorando las alternativas disponibles e inventar otras nuevas. Se ha obtenido acuerdos consistentes; falta asegurar una planificación rigurosa que se traduzca en un vuelco de las prácticas del sector petrolero, y en programas sostenibles y multiculturales de desarrollo ${ }^{38}$.

Las comunidades del Napo son conscientes de la precaria situación de otros bloques donde no hubo consulta previa; pero sus respuestas pretenden ser distintas en su propio territorio, porque esperan que cambien también las actitudes de las petroleras y del mismo Estado (ver 'propuestas') y demandan, para ello, el reconocimiento y el apoyo de la sociedad civil, además del Estado y de las compañías. El pasado no tiene que volver a repetirse.

\section{CONCLUSIONES}

Ha sido la primera vez que se lleva a cabo en el país un proceso de esta naturaleza, centrado en una temática cuya naturaleza dificultaba una toma de posición equilibrada.

Sin embargo, a pesar de su tremenda complejidad organizativa y de haber tenido lugar en un momento incierto, el proceso de Consulta Previa ha estado dotado de la mayor legitimidad:

- se ha contado con el previo aval de todas las organizaciones del área antes de iniciar el proceso;

- ha existido un activo involucramiento de todos los niveles de las organizaciones en los talleres de capacitación, con un alto porcentaje de participación;

- la mayoría de los participantes han manifestado que el haber sido tomados en cuenta por primera vez para ser capacitados y consultados, constituye un hecho sin precedentes para la región;

- la mayoría de las comunidades han emitido pronunciamientos válidos;

- el proceso ha sido validado por las Asambleas Intercomunales, y el Comité de Presidentes de Federaciones y Juntas Parroquiales;

- los resultados de la Consulta han sido aprobados por el Estado.

Por otra parte, es necesario subrayar que, a raíz del proceso de Consulta, todas las Federaciones y Juntas Parroquiales han convergido por 
primera vez en la historia de la región, y han puesto los cimientos de una fructífera colaboración futura en el marco del Comité de la Nacionalidad Kichwa del área de los bloques.

Sin embargo, quedan por ser absueltos una serie de retos importantes para las organizaciones y para el mismo Estado, relacionados con el cumplimiento de las demandas indígenas y con la continuación misma del proceso, de manera que se mantenga y refuerce la incipiente unidad, y se fortalezca la capacidad de las instituciones locales para apoyar a sus bases en un momento decisivo para el futuro de la región, incorporando apropiadamente a la minoría que se ha pronunciado contra el petróleo.

En esta dirección, es necesario subrayar que, en adelante, no está ya en cuestión la toma de posiciones a favor o en contra del petróleo en el área de los bloques, sino la convocatoria de todos los sectores del Estado y la sociedad civil para hacer posible un proceso petrolero con plena participación de las comunidades locales, que minimice los riesgos socio-ambientales, que incorpore procedimientos participativos y de vigilancia social en todas sus etapas, que respete las 'áreas sensibles' de las comunidades, y que contribuya eficazmente a una mejor distribución del ingreso, susceptible de dinamizar el desarrollo de los pueblos indígenas de la región. 